\title{
Activity patterns of cochlear ganglion neurones in the starling
}

\author{
G.A. Manley, O. Gleich, H.-J. Leppelsack, and H. Oeckinghaus \\ Institut für Zoologie der Technischen Universität München, Lichtenbergstrasse 4, D-8046 Garching, \\ Federal Republic of Germany
}

Accepted June 7, 1985

Summary. 1. Spontaneous activity and responses to simple tonal stimuli were studied in cochlear ganglion neurones of the starling.

2. Both regular and irregular spontaneous activity were recorded (Figs. 1 to 5). Non-auditory cells have their origin in the macula lagenae. Mean spontaneous rate for auditory cells (all irregularly

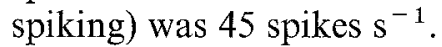

3 . In half the units having characteristic frequencies (CFs) $<1.5 \mathrm{kHz}$, time-interval histograms (TIHs) of spontaneous activity showed regularly-spaced peaks or 'preferred' intervals. The spacing of the peak intervals was, on average, $15 \%$ greater than the CF-period interval of the respective units (Fig. 11).

4. In TIH of lower-frequency cells without preferred intervals, the modal interval was also on average about $15 \%$ longer than the CF-period interval (Fig. 11). Apparently, the resting oscillation frequency of these cells lies below their CF.

5. Tuning curves (TCs) of neurones to short tone bursts show no systematic asymmetry as in mammals. Below $\mathrm{CF} 1 \mathrm{kHz}$, the low-frequency flanks of the TCs are, on average, steeper than the high-frequency flanks. Above CF $1 \mathrm{kHz}$, the reverse is true (Fig. 15).

6 . The cochlear ganglion and nerve are tonotopically organized. Low-frequency fibres arise apically in the papilla basilaris and are found near non-auditory (lagenar) fibres (Figs. 2 and 19).

7. Discharge rates to short tones were monotonically related to sound presure level (Fig. 20). Saturation rates often exceeded 300 spikes $\mathrm{s}^{-1}$.

8. 'On-off' responses and primary suppression of spontaneous activity were observed (Figs. 22 and 23).

Abbreviations: $C F$ characteristic frequency; $T C$ tuning curve; TIH time interval histogram
9. A direct comparison of spontaneous activity and tuning-curve symmetry (Fig. 15b) revealed that, apart from quantative differences, fundamental qualitative differences exist between starling and guinea-pig primary afferents.

\section{Introduction}

The investigation of the functional mechanisms of hearing in the inner ear of terrestrial vertebrates has, especially in the last 15 years, been greatly enriched through increased interest in hearing in nonmammals. The structural variety displayed in many nonmammalian groups offers fruitful ground for the investigation of structure-function relationships in the peripheral auditory apparatus and the evolution of hearing systems (Manley 1973, 1981; Miller 1980). Furthermore this comparative approach has attracted growing attention since peripheral auditory processing, which depends strongly on characteristics of hair cells, can often be more easily investigated in nonmammals. Thus the nonmammalian ear is attractive for those interested in finding a 'simple' experimental model for the mammal's ear.

The birds are the only nonmammalian group which have developed both a complex inner ear and highly complex vocalizations. Since the reptilian groups ancestral to birds and to mammals diverged about 250 million years ago - at the beginning of the great adaptive radiation of the reptiles - it is intriguing to study the structural and functional solutions to similar auditory problems found in modern representatives of the birds and mammals. The structural differences are substantial: elucidation of the functional consequences will help in identifying the evolutionary significance of 
the differences in the ears of the vertebrate groups. The songbirds offer the opportunity to investigate the processing of species-specific vocalizations in the inner ear and through the various neuronal levels in the brain (see e.g., Konishi 1970; Leppelsack 1978; Sachs and O'Connell 1983; Sachs et al. 1980 a; Scheich et al. 1983).

Neurophysiological investigations of auditorynerve units in birds have been carried out in pigeons, starlings and redwing blackbirds (Gross and Anderson 1976; Manley 1979, 1980; Manley and Gleich 1984; Manley and Leppelsack 1977; Sachs et al. 1974, 1978, 1980a, b). From these studies several general conclusions emerged. All auditory afferents have been shown to be spontaneously active in the absence of stimuli and to discharge irregularly. Within the spontaneous activity of the lower-frequency fibres preferred intervals may be present. Typically, the mean rates of spontaneous and evoked discharge in avian afferents are higher than in mammals. Phase-locking in fibres of the redwing blackbird is almost the same as in the cat (decreasing with frequency up to about $6 \mathrm{kHz}$; Sachs et al. 1980a, b). Finally, tuning curves of single avian afferents are $\mathrm{V}$-shaped, with selectivity ( $Q_{10 \mathrm{~dB}}$ values) similar to comparable mammalian fibres (Manley and Leppelsack 1977; Sachs et al. 1974).

We report here that, contrary to the generallyassumed similarity between tuning curves of mammal and bird, there is a fundamental difference in their symmetry. Indeed, the sugestion that auditory-nerve responses in birds are only quantitatively different to those in mammals (Sachs et al. $1980 \mathrm{a}$; Saito 1980) is challenged in the discussion below. At least with regard to tuning-curve symmetry and the patterns of spontaneous activity in the starling there exist important qualitative differences. To clarify the differences in tuning curves, we include a direct comparison with guinea-pig data.

The present paper describes aspects of the response activity of the auditory-nerve fibres of the starling so as to augment the amount of information available on the activity patterns of bird primary auditory neurones. Such data is essential for comparisons of structure-function relationships in other vertebrate groups, in an attempt to reach a holistic understanding of the vertebrate ear.

\section{Material and methods}

The results of the present study were obtained using 92 wildcaught starlings (Sturnus vulgaris) of both sexes, weighing between 63 and $94 \mathrm{~g}$. The birds were anaesthetized by intra-pec- toral injection of pentobarbital-sodium (Nembutal, initial dose $90-120 \mathrm{mg} / \mathrm{kg}$ body weight). Feathers were removed from the back of the head and from under the neck. A cannula was inserted into the trachea, and a large opening was made in an abdominal air sac to allow a continuous stream of moist air to pass into the cannula, through the lungs and out from the opened air sac. With artificial ventilation, the animals ceased spontaneous breathing (Schwartzkopff and Bremond 1963). During the experiments, anaesthesia was maintained by supplementary doses of Nembutal. Body temperature was regulated at 40 to $42^{\circ} \mathrm{C}$, as measured at the pectoral muscle. In order to compensate any water loss caused by the air stream, birds were given about $2 \mathrm{ml}$ of water to drink before anaesthesia, and/or bird Ringer solution $(9.0 \mathrm{~g} \mathrm{NaCl}, 0.42 \mathrm{~g} \mathrm{KCl}, 0.25 \mathrm{~g}$ $\mathrm{CaCl}_{2}$, ad $1,000 \mathrm{ml}$ aqua dest.) was injected sub-cutaneously into the back: the solution was either continuously infused $(1 \mathrm{ml} / \mathrm{h})$ during the experiment or doses of $1 \mathrm{ml}$ were injected before and during the experiment. The electrocardiogram was monitored during the experiment via electrodes in the neck and a hindlimb, as a measure of the animal's physiological condition and of the depth of anesthesia. After clearing the skin and muscles from the back of the skull, a metal rod was fixed to the bone by dental cement, enabling the head to be immobilized. Using a dorso-lateral approach, bone overlying the middle ear cavity was removed (see e.g. Schwartzkopff and Bremond 1963) to expose the basal part of the cochlea. The inner ear was opened in the region of the recessus scalae tympani, taking care that the cochlear partition and the branchlets of the cochlear artery in scala tympani were not damaged. The cochlear ganglion then became visible as a white band deep in the scala tympani.

Following surgery the animal was placed in an electricallyshielded anechoic chamber. Action potentials of cochlear ganglion neurones were recorded using glass micropipettes. The electrodes were advanced in $1 \mu \mathrm{m}$ steps using a hydraulic microdrive, and in some cases by an additional piezo-electric stepper. The pipettes were filled with $3 \mathrm{~mol} / 1$ sodium or potassium chloride or potassium acetate solution and had resistances between 15 and $60 \mathrm{M} \Omega$. The reference electrode was inserted into the neck musculature. Spikes were amplified and fed to an oscilloscope and an audiomonitor. For further photographic and computer processing the spikes, stimulus, stimulus trigger and voice commentary were recorded on magnetic tape.

Stimuli consisted of white- or pink-noise search sounds and tone bursts. These were typically of $40-50 \mathrm{~ms}$ duration, with $2 \mathrm{~ms}$ rise/fall time, delivered at a rate of 4 stimuli $\mathrm{s}^{-1}$. Stimuli were delivered in free field conditions. Sound pressure was calibrated (re. $2 \cdot 10^{-5} \mathrm{~Pa}$ ) using a condenser microphone placed next to the ipsilateral ear opening.

Tone-response thresholds were determined using audiovisual criteria; in difficult cases this was supplemented visually by storing several successive sweeps on a storage oscilloscope. The characteristic frequency $(\mathrm{CF})$ of the auditory neurones was determined in steps of 10,50 or $100 \mathrm{~Hz}$ for low-, mediumor high-CF fibres, respectively. During the collection of spontaneous activity, the sound delivery was terminated, normally by turning off the power to the amplifier driving the speaker. In a number of cases, units were additionally exposed to a taped programme of natural vocalizations. The responses to the vocalizations are being subjected to detailed analysis and will be reported at a later date (Leppelsack, Manley and Haeusler, in preparation).

The tape-recorded spike data were processed by a laboratory computer (Digital Equipment, PDP MINC 11/23). Interspike-time-interval (TIH), and peri-stimulus-time (PST) histograms were generated. Units which showed any peculiar bursting activity or an increase in spontaneous discharge rate during 

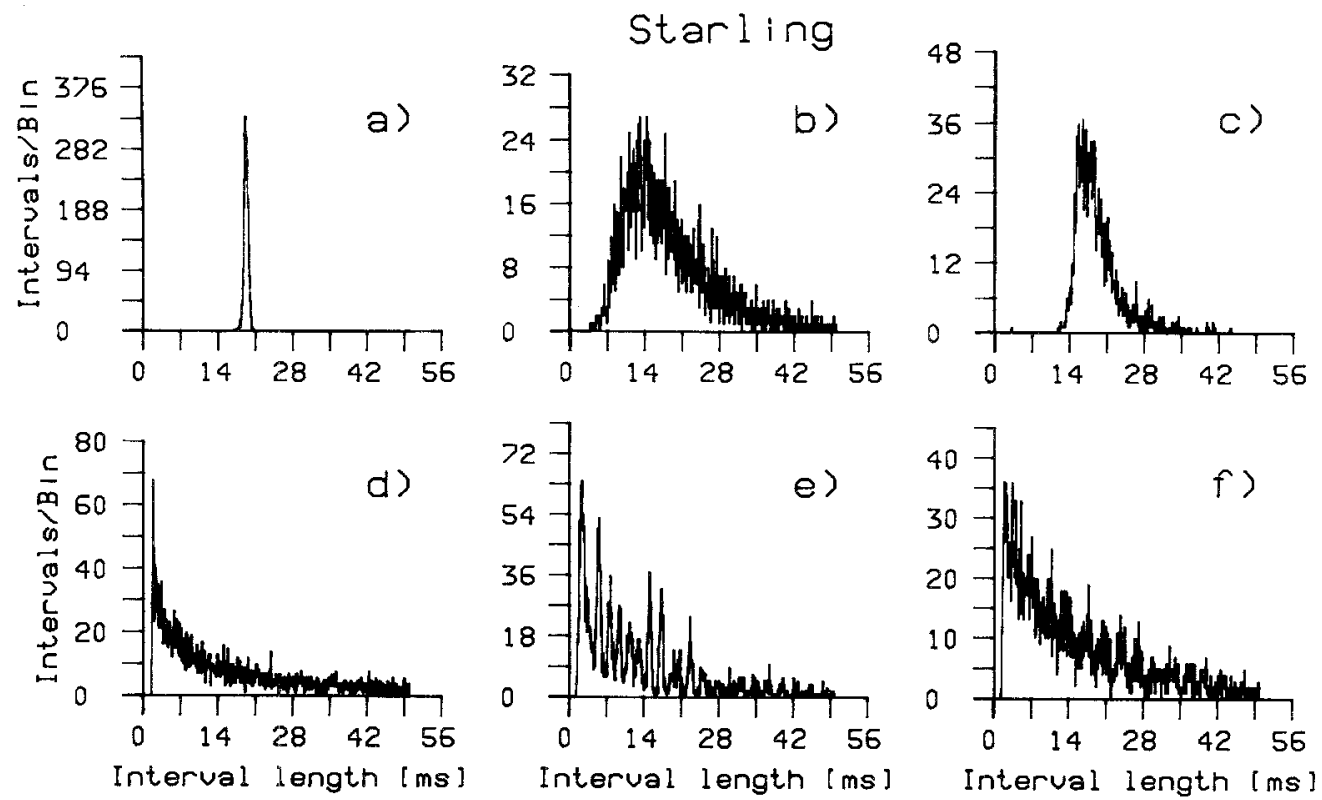

Fig. 1 a-f. Typical time-interval histograms (TIHs) of spontaneous activity in different neurones of the cochlear ganglion in the starling. a-c non-auditory; $\mathbf{d}-\mathbf{f}$ auditory cells. Among non-auditory neurones one can discriminate between regularly-firing (a) and irregularly-firing (b) cells. In a few cases, intermediate states (c) can be observed. Some auditory units show prominent (e), others less prominent (f) preferred intervals, whereas yet others exhibit no obvious preferred intervals. Bin width in all cases $0.1 \mathrm{~ms}$. Data for individual histograms are as follows (number of intervals, discharge rate in spikes/s): a 3,100, 51.8; $\mathbf{b}$ $2,940,52.4$; c $2,100,52.5 ;$ d $3,635,42.7$, CF $1.8 \mathrm{kHz}$, threshold $48 \mathrm{~dB}$ SPL; e $3,851,68.1$, CF $0.4 \mathrm{kHz}$, threshold $21 \mathrm{~dB}$ SPL; f $3,763,55.2, \mathrm{CF} 0.25 \mathrm{kHz}$, threshold $57 \mathrm{~dB}$ SPL

the approach of the electrode were disregarded because such activity was assumed to be due to injury of the neurone (see e.g., Manley and Leppelsack 1977). Correlation coefficients between characteristics of the neuronal responses were calculated. Their significance was determined on the basis of the $1 \%$ confidence level (Table in Sachs 1970). It should be noted that, in the construction of figures, it often occurred that data points completely overlapped each other. In these cases, no attempt was made to make any adjustments to the positioning of points on the graphs.

\section{Results}

\section{Patterns of spontaneous activity}

Activity was recorded from over 500 neurones in the cochlear ganglion, although many more nonauditory units were encountered but not further investigated. Recording depth ranged from near the surface down to $600 \mu \mathrm{m}$, which reflects the approximate depth of this ganglion in birds (Boord and Rasmussen 1963). In the absence of acoustic stimuli, two kinds of spontaneous activity were recorded; regularly- and irregulary-firing cells (Fig. 1). All regularly-firing cells and some irregularly-firing cells did not respond to acoustic stimuli. All auditory neurones showed irregular spontaneous activity.

Non-auditory cells. As the nonmammalian cochlea contains the macula lagenae at its apical end, it was not surprising to find a thick band of nonauditory cells which lay apically and posteriorly in the ganglion. An analysis of the auditory cells found immediately prior or subsequent to non-auditory cells (Fig. 2) revealed that over threequarters of the non-auditory cells were found next to auditory cells whose $\mathrm{CF}$ was at or below $0.5 \mathrm{kHz}$. This was true for both regularly- and irregularly-firing non-auditory cells (Fig. 2).

Units which did not respond to noise or test tones in the frequency range 0.1 to $5 \mathrm{kHz}$ ( 80 to $90 \mathrm{~dB}$ SPL) were classified as non-auditory. No special attempt was made to record the spontaneous activity of these cells, so we cannot estimate the size or activity of the population in comparison to auditory units. TIHs were generated for 15 regular and 10 irregular cells, whose discharge rates ranged between 12-62 spikes $\mathrm{s}^{-1}$ and 5-168 spikes $\mathrm{s}^{-1}$, respectively. It is not possible to fully exclude the possibility that some of the irregularly-firing non-auditory cells were actually auditory cells with very high thresholds or with a CF below $100 \mathrm{~Hz}$. However, more than two thirds of these irregularly-firing non-auditory cells had TIHs (Fig. 1 b) which differed greatly from the TIHs of auditory cells (Fig. 1d-f), making it highly unlikely that they were auditory. For the purposes of this analysis, all these cells were treated as non-auditory.

Two of the regularly-firing cells showed a de- 


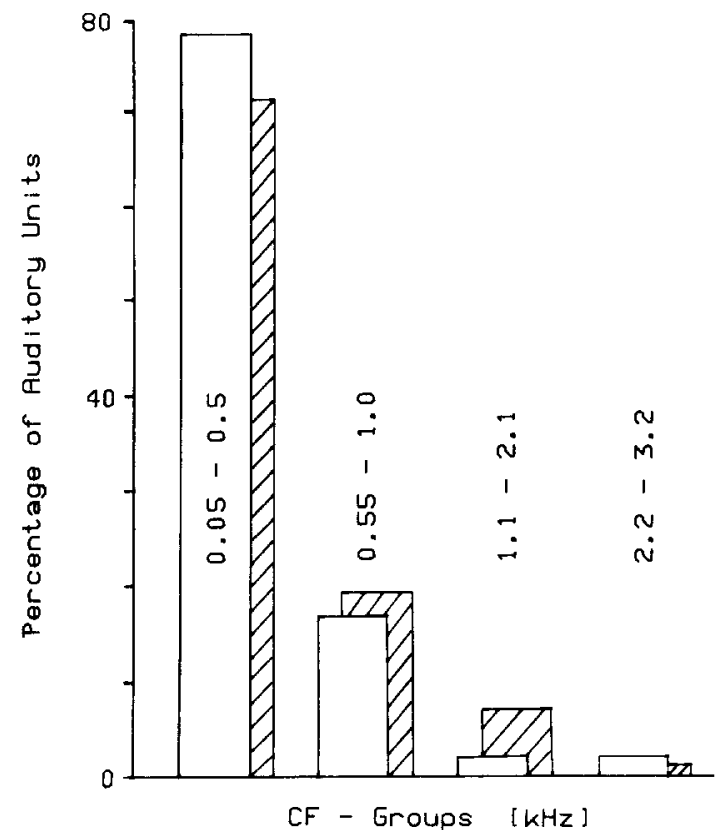

Fig. 2. Analysis of spatial relationship between auditory and non-auditory cells in the starling cochlear ganglion. This diagram only includes those auditory units which were "neighbours' of non-auditory cells. 'Neighbour' was defined as follows: the neighbours of a non-auditory unit were those auditory cells which were recorded in the same penetration either adjacent to or two cells away (before or after) from this non-auditory cell. The cells were placed in four classes, according to their respective $C F$. Each $C F$ class was further divided into two, according to whether the non-auditory neighbour showed regular (unhatched bars) or irregular (hatched bars) spontaneous activity. In both cases, the total number of auditory units was normalized to $100 \%$. It should be noted that this analysis counts auditory neurones which were 'neighbours' of more than one non-auditory unit once for each occurrence (for regular units total number of cases $=59$; for irregular $=124$ )

viation from the highly compact Gaussian distribution (where the mode and mean interval are identical) shown in Fig. 1a; for these cells, the spread of intervals for a given rate was higher, especially towards longer intervals (Fig. 1c). In these cases, the average interval was no longer the same as the mode of the histogram, but some $20 \%$ longer. Our impression was that it was much easier to 'hold' non-auditory cells; their spike size was often significantly larger than for auditory cells, which may indicate that the axons or cell bodies were larger. In the pigeon, larger axons are more common in the lagenar portion of the auditory nerve than in the cochlear division (Boord and Rasmussen 1963).

Auditory cells. All auditory cells were spontaneously active, with rates (counted for 188 cells) between 4.9 and 157 spikes $\mathrm{s}^{-1}$. The mean rate was 45 spikes s$^{-1}$ (Fig. $3 \mathrm{a}$ ). It is clear that the distribu-

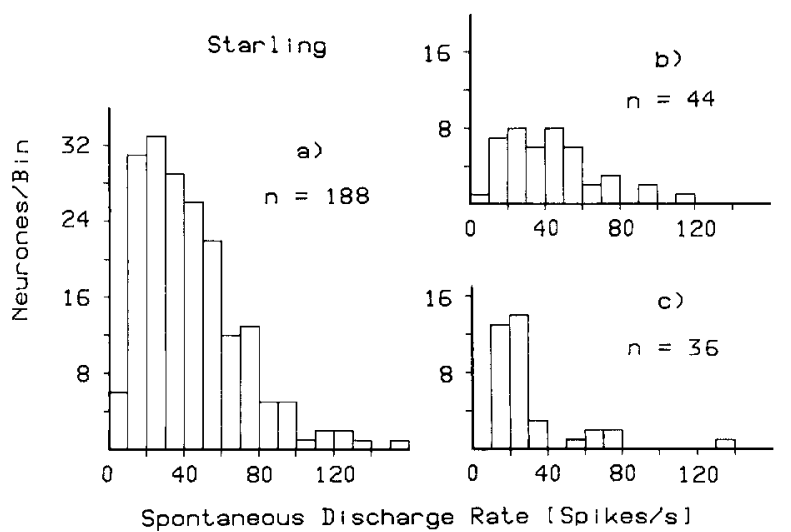

Fig. 3. a Distribution of mean discharge rates in spontaneous activity in 188 auditory cells in the cochlear ganglion. b Mean rates of auditory neurones with tone-response thresholds above $50 \mathrm{~dB}$ SPL from animals in which cells with lower thresholds also occurred. c Mean rates of auditory neurones from animals in which all cells had thresholds above $50 \mathrm{~dB}$ SPL. Whereas the distribution in $\mathbf{b}$ reflects that in $\mathbf{a}$, the histogram in $\mathbf{c}$ indicates that in animals in which all thresholds exceeded $50 \mathrm{~dB}$ SPL, spontaneous rates were unusually low. On this basis, data from these 'insensitive' animals were treated separately. Ordinate is number of neurons per bin. Binwidth 10 spikes/s

tion of rates is unimodal and that the very low rates of spontaneous activity found in some mammalian fibres are absent.

In order to take into account the fact that the spontaneous rate depends on the physiological condition of the animal, a similar criterion for the animal's condition was applied as used by Manley and Robertson (1976). They used a lowest threshold of more than $50 \mathrm{~dB}$ SPL as a criterion level for damaged cells. However, in the starling low-CF cells never had low thresholds and many individual animals showed a large spread of thresholds (see below). Only $2.5 \%$ of cells from sensitive animals had thresholds over $70 \mathrm{~dB}$ SPL, whereas $50 \%$ of cells from insensitive animals had thresholds of greater than $70 \mathrm{~dB}$. Neurones from animals showing thresholds of greater than $50 \mathrm{~dB}$ for all cells (insensitive animals) were therefore analyzed separately (Fig. 3c). These were compared to neurones with thresholds $>50 \mathrm{~dB}$ in sensitive animals (Fig. 3 b). Sensitive animals also had neurones with thresholds $<50 \mathrm{~dB}$. The distribution of rates in Fig. $3 c$ differs strongly from the distributions in Fig. $3 \mathrm{a}$ and $\mathrm{b}$. This difference suggests that insensitive animals exhibited responses from cells in poor physiological condition, and therefore justifies treating data from insensitive animals separately. Although we cannot exclude the possibility that the elevated thresholds encountered in some cells of otherwise sensitive animals are also abnormal, we consider this unlikely, as it can be seen in 


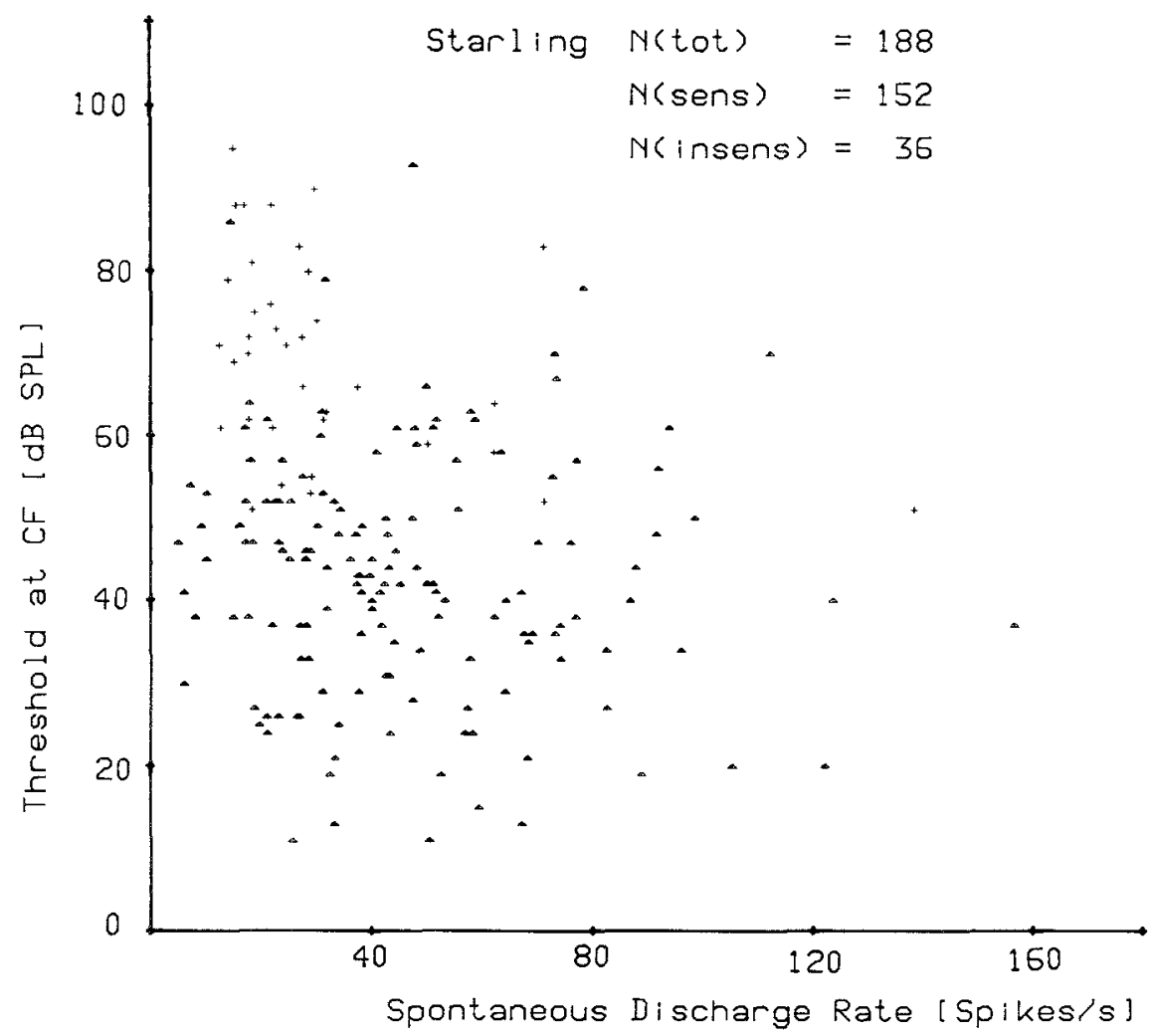

Fig. 4. Correlation between spontaneous discharge rate and lowest threshold in 188 auditory cells. Triangles: data for cells in sensitive (sens) animals. Crosses: data for cells in insensitive animals (insens = all rate thresholds above $50 \mathrm{~dB}$ SPL). When the extreme values of cells from insensitive animals are ignored, there is no correlation between the two variables

Fig. $3 b$ that their rates do not differ from those shown by the whole cell population (Fig. 3a). Excluding the cells from insensitive animals (Fig. $3 \mathrm{c}$ ) from the analysis changes the average spontaneous rate from 45 to 48 spikes $^{-1}$. Thus, it is reasonable to conclude that the 'normal' mean rate of spontaneous activity of primary auditory neurones is 48 spikes $\mathrm{s}^{-1}$. It should be noted, however, that all high-threshold units, including those from 'insensitive' animals, showed no abnormalities in the characteristics of their interval histogram; e.g., mode, dead time, interval distribution.

When the data from the group of insensitive animals is ignored, the spontaneous rate is not correlated with unit threshold at CF (Fig. 4). In addition, there is a tendency for the spontaneous rates of cells to correlate with their $\mathrm{CF}$, where higher-CF cells have lower spontaneous rates (Fig. 5). This has also been observed in nerve fibres of the redwing blackbird (Sachs MB, personal communication).

Spontaneous rate and interval distributions in TIH. The frequency of occurrence of intervals longer than the mode falls off approximately exponentially with increasing interval length (quasi-Poisson

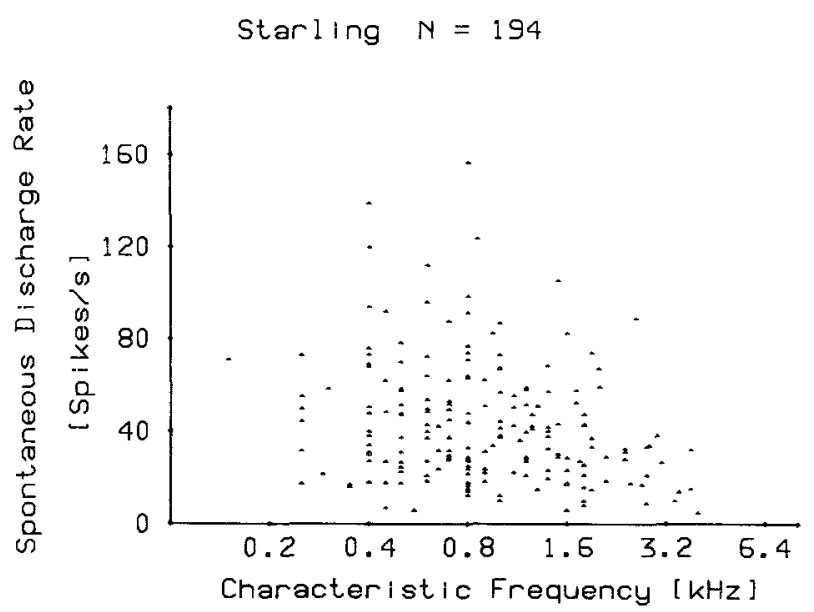

Fig. 5. Distribution of spontaneous discharge rates for $194 \mathrm{au}-$ ditory cells of different CFs of the starling cochlear ganglion. $r=-0.2309$, significant at the $1 \%$ level

distribution). However, a cell's refractory period excludes very short intervals, so that the Poisson distribution is truncated (see e.g., Fig. 6).

The fact that interval histograms resemble Poisson distributions supports the supposition that the length of an interval is independent of the length of the preceding interval(s). An additional, 

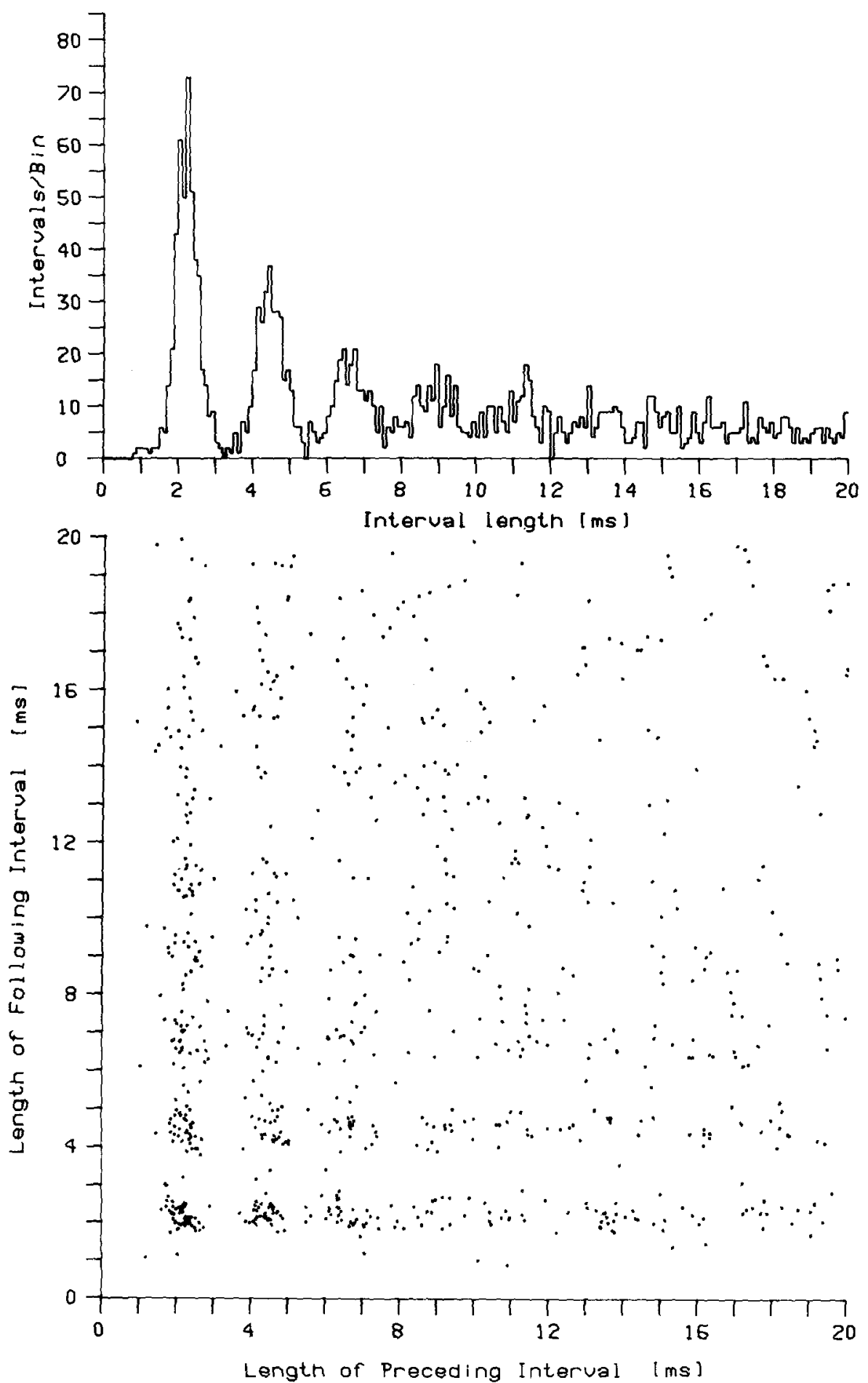

Fig. 6. TIH and joint-interval histogram for the spontaneous activity of an auditory neurone which showed preferred intervals. For the case of a cell not showing preferred intervals, there would appear to be complete randomness in the order of appearance of intervals of different lengths, within the limits set by the overall

frequency of occurrence of long and short intervals. In the cell illustrated here, some intervals occur much more frequently than those intervals between, but do not occur almost exclusively following each other as, e.g., in injury bursts

direct test of this conjecture is to construct a jointinterval histogram.

The pattern shown by a cell with prominent preferred intervals is shown in Fig. 6. Although intervals near $2.25 \mathrm{~ms}, 4.5 \mathrm{~ms}, 6.75 \mathrm{~ms}$ etc., occur much more frequently than those intervals between they do not occur almost exclusively following each other (as e.g., in injury bursts) but appear preferentially before or after intervals of all lengths.

In one series of experiments, the rate of decay of the interval frequency for longer intervals was studied. With semi-logarithmic TIH, where an exponential decay produces a straight line plot, there is a tendency for the decay to be faster than exponential up to intervals of about $15 \mathrm{~ms}$, then slower 


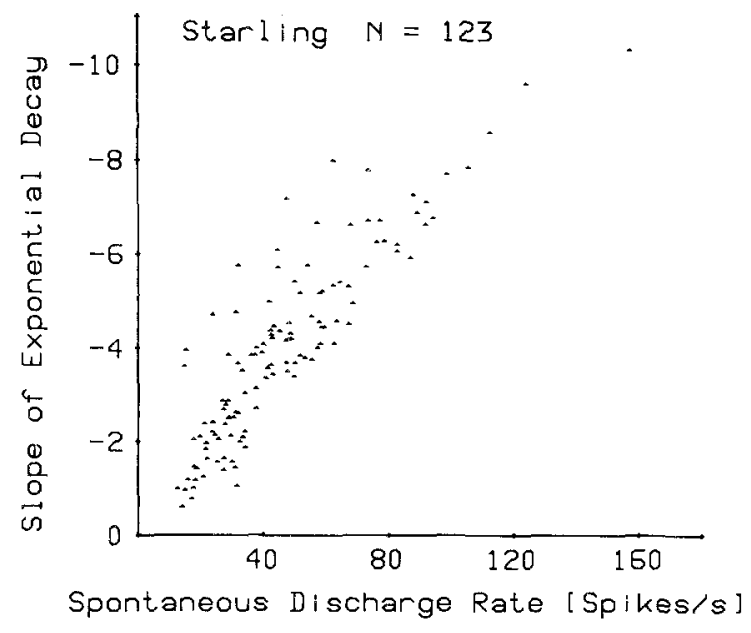

Fig. 7. The spontaneous discharge rate of auditory neurones and the slope of the decay of interval frequency in the respective TIHs are closely correlated. The steepness of the slope for normalised TIH was measured by calculating a regression line for each TIH from the numbers of intervals occurring in sequential $2 \mathrm{~ms}$ time bins. The slope is given in arbitrary units
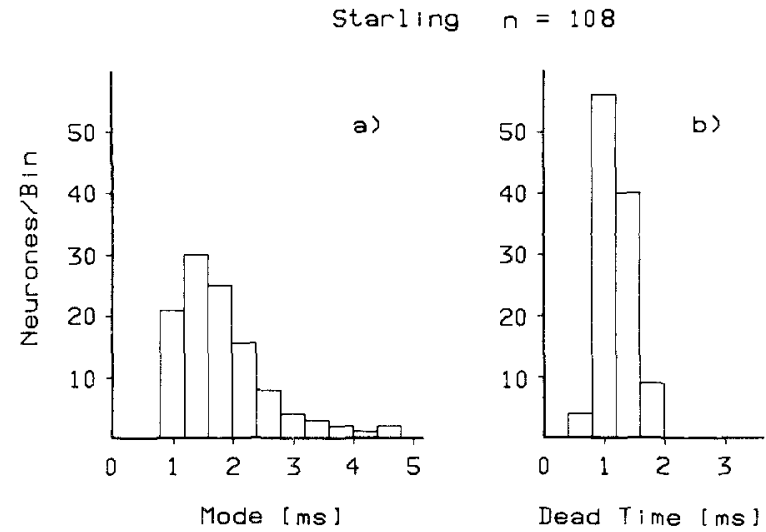

Fig. 8a, b. Distribution of most frequent intervals - modes (a), and dead times - shortest intervals - (b) in TIHs of 108 auditory neurones

than exponential for longer intervals. Since the interval frequency falls off approximately exponentially, the slope of the exponential decay was calculated for 123 units by regression analysis. In most cases, the slope of the decay was predictable from the known spontaneous rate (Fig. 7). Some of the units in Fig. 7, however, showed a much steeper slope than would be expected from their spontaneous rate. This observation was not correlated with any other known characteristic of these cells (e.g., threshold).

The mode or most common interval. In TIHs of units where sufficient data were collected (more than 2,000 intervals total or 1,000 intervals shorter than $10 \mathrm{~ms}$, number of cells =108) the position of
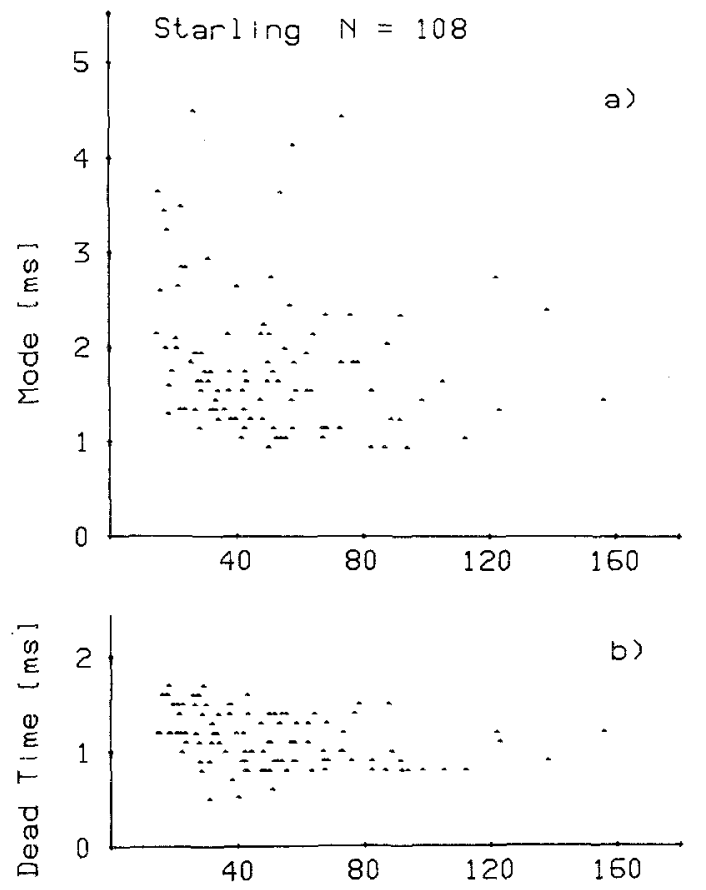

Spontaneous Discharge Rate [Spikesis]

Fig. 9a, b. Correlation of mean spontaneous discharge rate with mode (a) and dead time (b) in TIHs of 108 auditory cells

the mode was independent of small changes in the bin width chosen for the TIH analysis $(0.05$ or $0.1 \mathrm{~ms}$ ). Modes were found between 0.95 and $4.6 \mathrm{~ms}$ (Fig. 8a). Most neurones displayed a mode between 1 and $2 \mathrm{~ms} ; 20 \%$ showed modes longer than $2.3 \mathrm{~ms}$. These latter neurones had a 'shoulder' or relative maximum at an interval approximately half that of the mode. There was no obvious correlation between the spontaneous rate and the modes or dead times of TIH's (Fig. 9).

The relationship between the mode of the interval distribution and CF is shown in Fig. 10. There is a significant correlation between mode and CF, such that, on average, low-CF units have longer modes than high-CF units. In order to further investigate this interesting fact, the modes were compared to the CF-period (1/CF) by calculating the product of $\mathrm{CF}$ and mode for each unit (Fig. 11d). In most cases, mode and $\mathrm{CF}$-period are nearly the same and their product is thus close to 1 . In some other cases, the product is about 2 . Thus, in many cases, the mode of TIH of spontaneous activity reflects the tuning properties of the cell to sound stimuli, i.e., the $\mathrm{CF}$. The peak of the distribution of the product of mode and $\mathrm{CF}$ lies conspicuously above 1.0 (Fig. 11d). The mode is, on average, slightly longer (10-20\%) than the CF-period.

All units with modes of the TIH greater than $2.3 \mathrm{~ms}$ showed a 'shoulder' in the interval histo- 


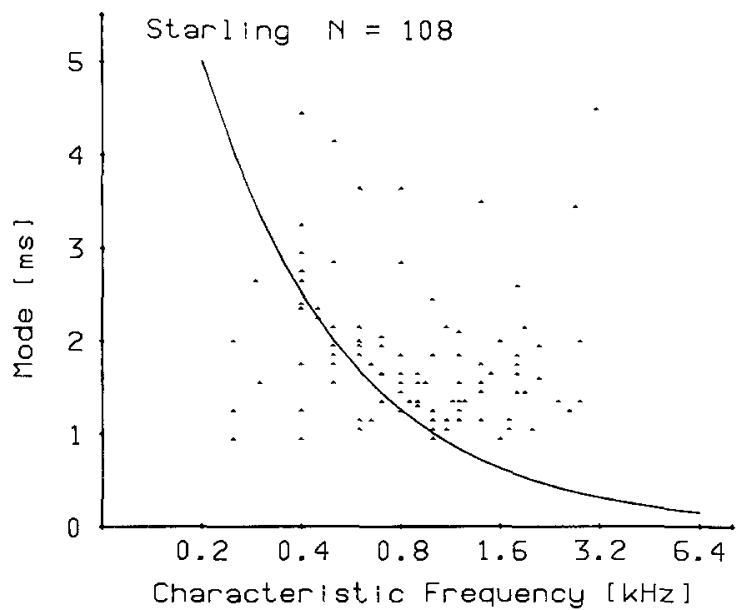

Fig. 10. Mode plotted against CF for 108 auditory neurones. There is a concentration of data points somewhat to the right of the line representing the value $1 / \mathrm{CF}$ ( $\mathrm{CF}$ period). For units $<1.5 \mathrm{kHz}$, where preferred intervals can occur, $\mathrm{r}=-0.2965$, significant at the $1 \%$ level

gram at an interval of half the mode. For comparison, two units, one showing such a shoulder, are shown in Fig. $11 \mathrm{~b}$ and $11 \mathrm{c}$. Their spontaneous rates and CFs were very nearly the same, as were their thresholds. The interval duration of the 'shoulder' corresponds to the mode of a unit with a 'normal' interval distribution.

As no modes shorter than $0.9 \mathrm{~ms}$ were found, the relationship described above cannot hold for cells with CF above $1 \mathrm{kHz}$. These very short intervals must to some extent be influenced by the cell's refractory period.

Dead times. The dead time of an interval histogram simply describes the shortest interval which occurred during the recording period. Dead times occurred between 0.5 and $2.2 \mathrm{~ms}$; the bulk, however occurred relatively evenly distributed between 0.8 and $1.6 \mathrm{~ms}$ (Fig. $8 \mathrm{~b}$ ). A comparison of the action potentials in extreme cases of long and short dead times revealed no correlation with differences in spike duration.

Dead time was not significantly correlated with spontaneous discharge rate (Fig. 9 b). When mode is plotted against dead time, it can be seen that cells with short modes (typically correlated with $\mathrm{CF}$ below $1 \mathrm{kHz}$ ) cluster together (Fig. 12). Therefore, there is a strong correlation between the mode and the dead time, the most common interval being approximately $30 \%$ longer than the dead time. This is especially true if neurones with a 'shoulder' in the TIH (modes longer than $2.3 \mathrm{~ms}$ ) are ignored.

Preferred intervals. One third of units (about one half of units with $\mathrm{CF}$ below $1.5 \mathrm{kHz}$ ) showed a different pattern. In these units, the TIH showed several systematically-occurring relative maxima (or peaks) and minima. We call these maxima preferred intervals (Figs. $1 \mathrm{e}$ and $11 \mathrm{a}$ ). In some cases, more than 5 peaks occurred immediately following the mode. In other cases, peaks at intervals between 10 and $50 \mathrm{~ms}$ (10 to 15 peaks) were seen, not connected in the histogram to any peaks which occurred at short intervals (see e.g. Fig. 1f). Within each histogram, the positions of the peaks were highly consistent, variation of interpeak intervals greater than $5 \%$ was rare.

The distribution of preferred intervals was analysed independently of the mode. For each cell a 'basic interval' was calculated, as shown in Fig. 11 (see legend). The basic interval was then compared to the unit's CF - as for the mode, the basic interval was multiplied by the CF. On average, the basic interval was $10-20 \%$ longer than the CF-period, i.e. the product of $\mathrm{CF}$ and basic interval is greater than 1 (Fig. $11 \mathrm{e}$ ). A regression plot of basic interval against $\mathrm{CF}$-period revealed a strong correlation $(\mathrm{r}=0.716, n=37$, significant at the $0.1 \%$ level). Although the relationship between mode and CFperiod showed substantially greater spread than the basic interval and CF-period comparison (due to the inclusion of 'shoulder'-TIH and of high-CF units), the correlated behaviour of the mode and the basic interval is obvious (Fig. $11 \mathrm{~d}$ and e). It thus seems reasonable to regard the mode in these cells as a consistently-occurring preferred interval and to begin to look for the physiological bases of this rhythmical behaviour.

\section{Patterns of tone-evoked activity}

Rate thresholds of tone-evoked responses in primary-nerve units were determined audio-visually. In some cases these data were examined in comparison to peri-stimulus-time (PST) histograms constructed for tones below, at and above the audiovisual threshold. In these cases, it was confirmed that the audio-visual threshold was within 1 or $2 \mathrm{~dB}$ of the threshold of rate increases detectable in PSTs (increase equivalent to up to $40 \%$ depending on the spontaneous rate). We have recently found that in some cells a phase-locking sets in below this rate threshold. However, we do not yet have sufficient data to generalize on this phenomenon.

Tuning curves of single units. Tuning curves complete enough to permit measurement of slopes were obtained in 190 cells. In these cases, the form of the tuning curves was quantified by measuring the 

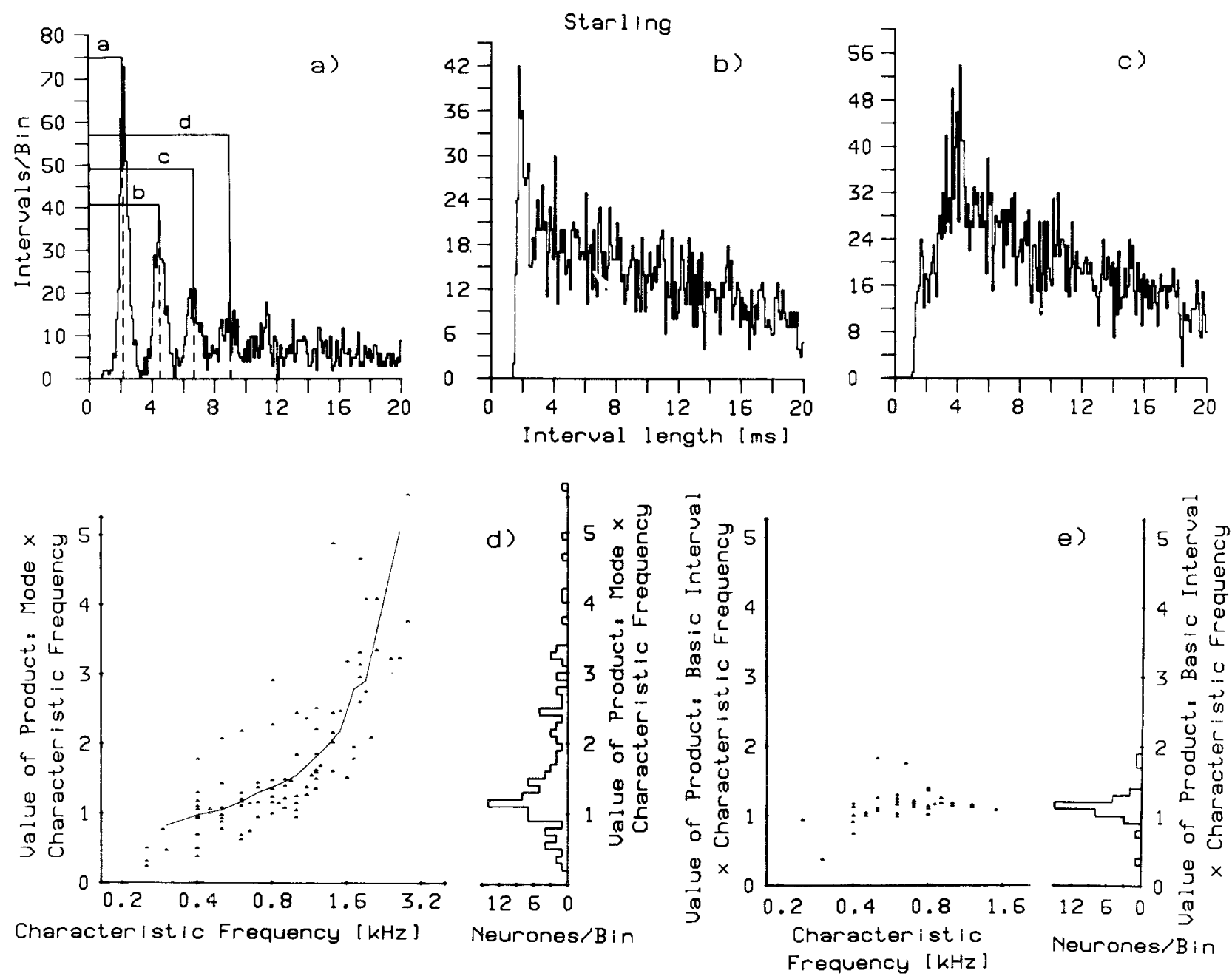

Fig. 11 a-e. The TIH in a shows preferred intervals in the spontaneous activity of an auditory cell. The lengths of these intervals were determined as indicated in $\mathbf{a}$ and a 'basic' interval was calculated using the formula: length of basic interval $=(\mathrm{b} / 2+\mathrm{c} / 3+\mathrm{d} / 4) / 3$. For each neurone, the product of $\mathrm{CF}$ and basic interval was then calculated. A perfect agreement between the basic interval and the CF-period of each neurone would result in a product value of 1 . In e these product values are plotted against the $\mathrm{CF}$ for 37 neurones. The distribution of product values (right side of e) shows that they are on average somewhat higher than 1. This is in good agreement with the result of a similar calculation of the product of the mode and CF in TIHs of 108 cells (d). The scatter towards higher product values in the distribution shown on the right side of $\mathbf{d}$ results partly from the inclusion of units with long modes in their 'shoulder'-type of TIH (c) as compared to a 'normal' TIH (b). The curve in d shows a three-point running average of the data of the scatter diagram. Data for individual units are as follows (Number of intervals, discharge rate in spikes/s, CF in kHz). a $1,873,48.6,0.45 ; \mathbf{b} 2,621,51.6,0.5 ; \mathbf{c} 3,832,57.8,0.5$

slope of the low- and high-frequency flanks below and above $\mathrm{CF}$ (between 3 and $23 \mathrm{~dB}$ above $\mathrm{CF}$ threshold).

The tuning curves possess a relatively simple ' $V$ '-shape (Fig. 13). The rate of loss of sensitivity with increasing disparity between the test-tone and the CF varies, however, from cell to cell and usually differs between the low and high flanks for one cell. The cells did not show the relatively consistent asymmetry of auditory nerve fibres of mammals (Fig. 14a, b), nor did the high-CF units show lowfrequency 'tails' as seen in mammals. On average, the tuning curves are almost symmetrical
(Fig. 14a). Although in this figure only 12 cells had quite symmetrical tuning curves (slope ratio 1), cells with a steeper high-frequency flank are just as frequent as cells with a steeper low-frequency flank. The tendency to steeper high- or low-frequency flanks is not consistent across $\mathrm{CF}$ (Fig. 15a). Whereas below $\mathrm{CF} 1 \mathrm{kHz}$ twice as many cells show a steeper low-frequency slope than show a steeper high-frequency slope (Fig. 15a), above $\mathrm{CF} 1 \mathrm{kHz}$, the situation is reversed. The difference to the situation in the guinea pig is obvious (Fig. 15b). In Fig. 16, it can be seen that, whereas the maximal values of high-frequency slope in- 


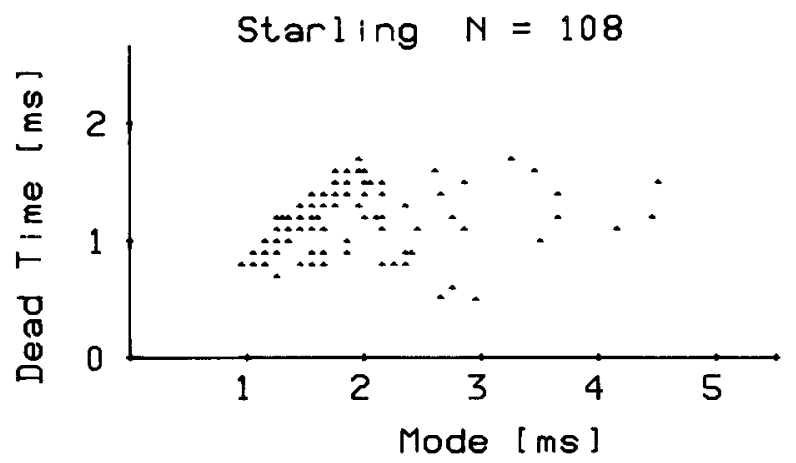

Fig. 12. Mode and dead time in spontaneous activity of 108 auditory neurones. In most of the cases the mode interval is about $30 \%$ longer than the dead time. $r=0.2994$, significant at the $1 \%$ level

creases steadily with increasing CF (Fig. 16a), the variability of the maximal low-frequency slope is much greater (Fig. 16b).

Tuning-curve sharpness is another common method of quantifying tuning-curve shape. The $Q_{10 \mathrm{~dB}}$ values were calculated for 234 cells (Fig. 17). While there is a tendency for the average $Q$ value to increase with $\mathrm{CF}$, this is partly due to the fact that at higher CFs, both high and low $Q$ values are present.

The range of $C F$ s and threshold. Characteristic frequencies were found in the range 0.15 to $4.2 \mathrm{kHz}$, the best threshold at $9 \mathrm{~dB}$ SPL (Fig. 18). The large spread of thresholds is due both to variation between animals and within one animal. In single animals a threshold spread up to $59 \mathrm{~dB}$ was observed ( 34 to $93 \mathrm{~dB}$ SPL at 0.6 and $0.5 \mathrm{kHz}$, respectively). In this case, the most insensitive cell was encountered early in the experiment, the most sensitive near the end. It is possible to exclude general degenerative effects on the animal, but not the effects of anaesthesia as an explanation for the large spread of thresholds. Most animals in which many cells were encountered showed total threshold ranges of $30-50 \mathrm{~dB}$. This spread is, however, partly due to the fact that low-CF cells always have higher thresholds (Fig. 18).

The distribution of $\mathrm{CFS}$ in the nerve. As can be seen in Fig. 18, units with extreme CF values were less often encountered than units in the middle frequency range $(0.4$ to $2 \mathrm{kHz})$. It is not reasonable to put much emphasis on this finding, however, for two reasons. Firstly, we seldom made an attempt to penetrate the ganglion systematically according to position and secondly, the CFs are organized non-randomly in the ganglion.

As was already noted for Fig. 2, non-auditory

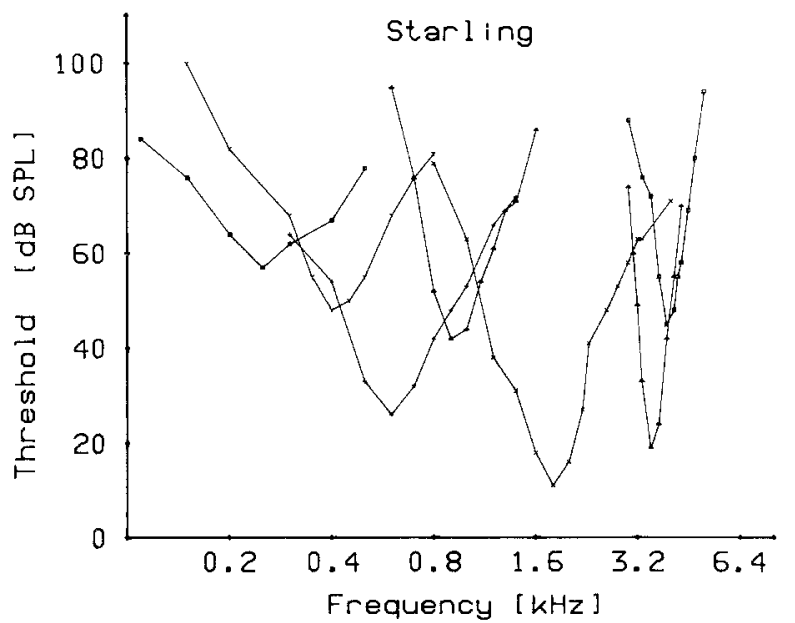

Fig. 13. Typical tuning curves of cochlear ganglion cells in the starling
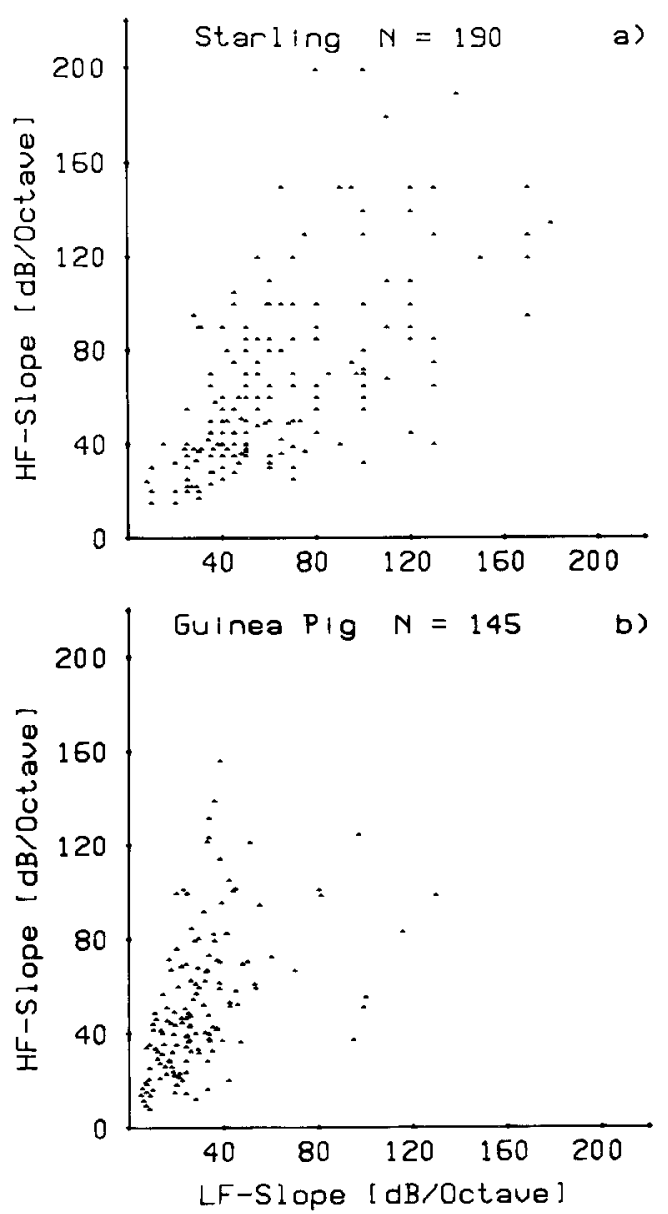

Fig. 14a, b. High- $(H F)$ and Low-frequency $(L F)$ slopes as a measure of symmetry relationships in tuning curves of primary auditory neurones of the same CF-range in the starling (a) and the guinea pig (b). Note that in contrast to the symmetrical distribution for the starling, most tuning curves in the guinea pig have steeper HF slopes. (Guinea-pig data courtesy of R. Harrison, Toronto) 

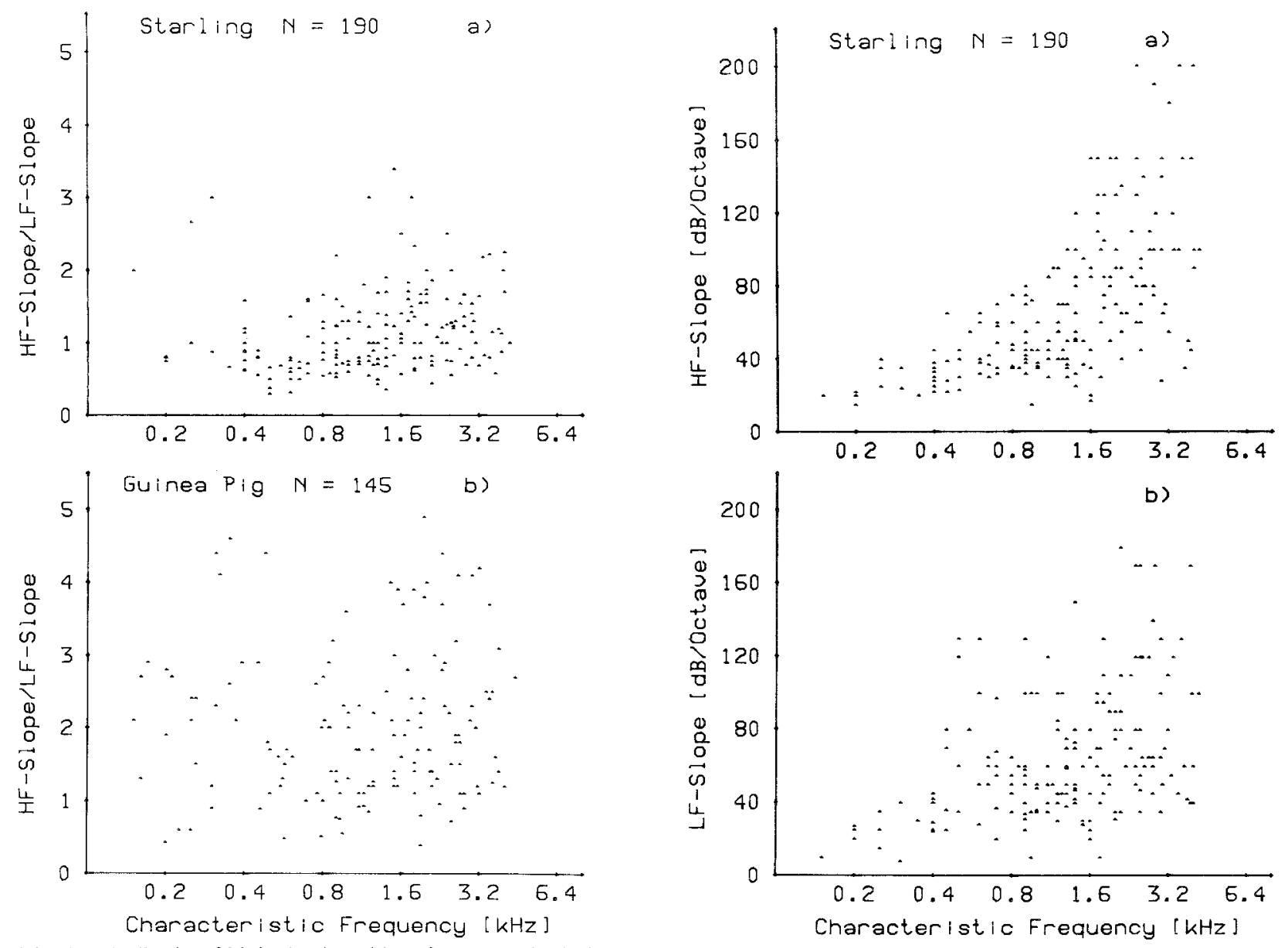

Fig. 15a, b. Ratio of high- $(H F)$ and low-frequency $(L F)$ slopes plotted against CF. In the starling (a) the ratio is generally closer to 1 than in the guinea pig (b), where the values are much higher over the whole frequency range, indicating a steeper HF-slope at all CFs. The starling data indicate that below CF $1 \mathrm{kHz}$, two-thirds of tuning curves have a steeper $\mathrm{LF}$-slope. Above $\mathrm{CF} 1 \mathrm{kHz}$, the reverse is true. (Guinea-pig data courtesy of R. Harrison, Toronto)

units seldom appeared as direct neighbours of units with CF above $0.5 \mathrm{kHz}$. The apical part of the cochlear ganglion contains only units with low CF. The CFs rose as the electrode penetrated more basally and nearer the basilar membrane. In the latter case, it was occasionally possible to penetrate fibre bundles leaving the basilar papilla before they entered the ganglion. Two factors limited the number of recordings from high-CF units. Firstly, the cochlear canal was opened in a region near its base so that any physiological damage and any fall in perilymph level would affect high-CF units preferentially. Secondly, the part of the ganglion serving the basal area is small and less accessible.

Single penetrations often encountered units of different CFs. In Fig. 19 we present a few of these

Fig. 16a, b. Correlation of high-frequency slope (a) and lowfrequency slope (b) with CF in starling cochlear ganglion cells. In both cases, the slopes of the tuning curves increase with $\mathrm{CF}$

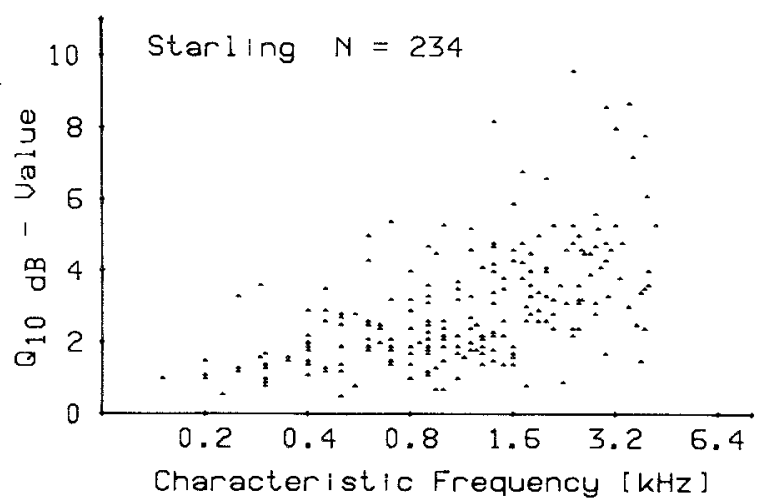

Fig. 17. $Q_{10 d \mathrm{~B}}$ values for tuning curves of 234 cochlear ganglion cells. The mean $Q_{10 \mathrm{~dB}}$-value increases with $\mathrm{CF}$

cases to illustrate how the CFs changed with depth. In some cases, the CF remained relatively constant (Fig. 19, left), in others the CF became higher (Fig. 19, centre) or became lower (Fig. 19, right) with depth. One or two penetrations showed a re- 


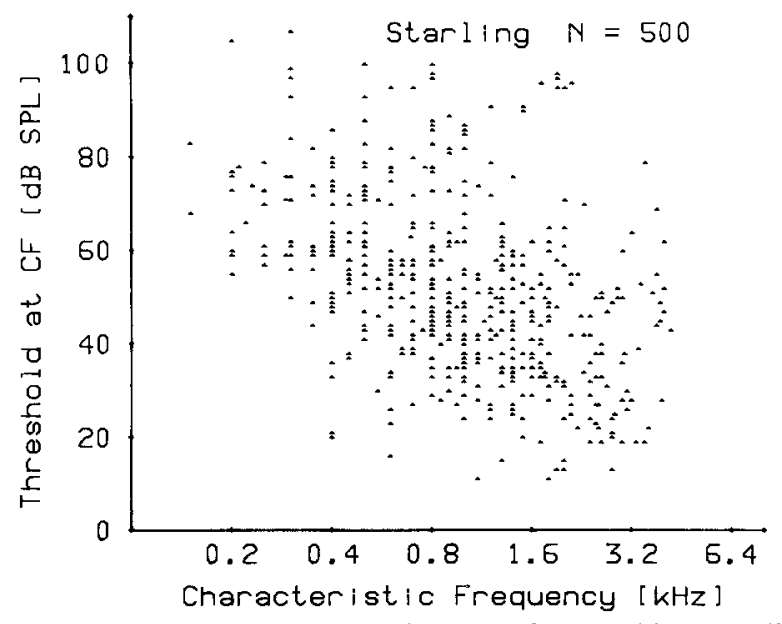

Fig. 18. Absolute rate thresholds at CF of 500 cochlear ganglion cells in the starling peating 'jump' in the CF range (Fig. 19, right and centre). These differences are due to the variation in the location and angle of electrode penetration. The fact that the CFs do vary systematically with depth and with location in the basal-apical axis, however, rather than showing a chaotic arrangement, supports the expectation from anatomical data that the ganglion is tonotopically organized.

Discharge patterns to single tones. PST histograms to tones just above threshold revealed tonic responses. However, with increasing sound-pressure level, the response of all cells became increasingly phasic-tonic. At saturation sound level the time course of the phasic component exceeded the stimulus duration (Fig. 20). Following the stimulus,
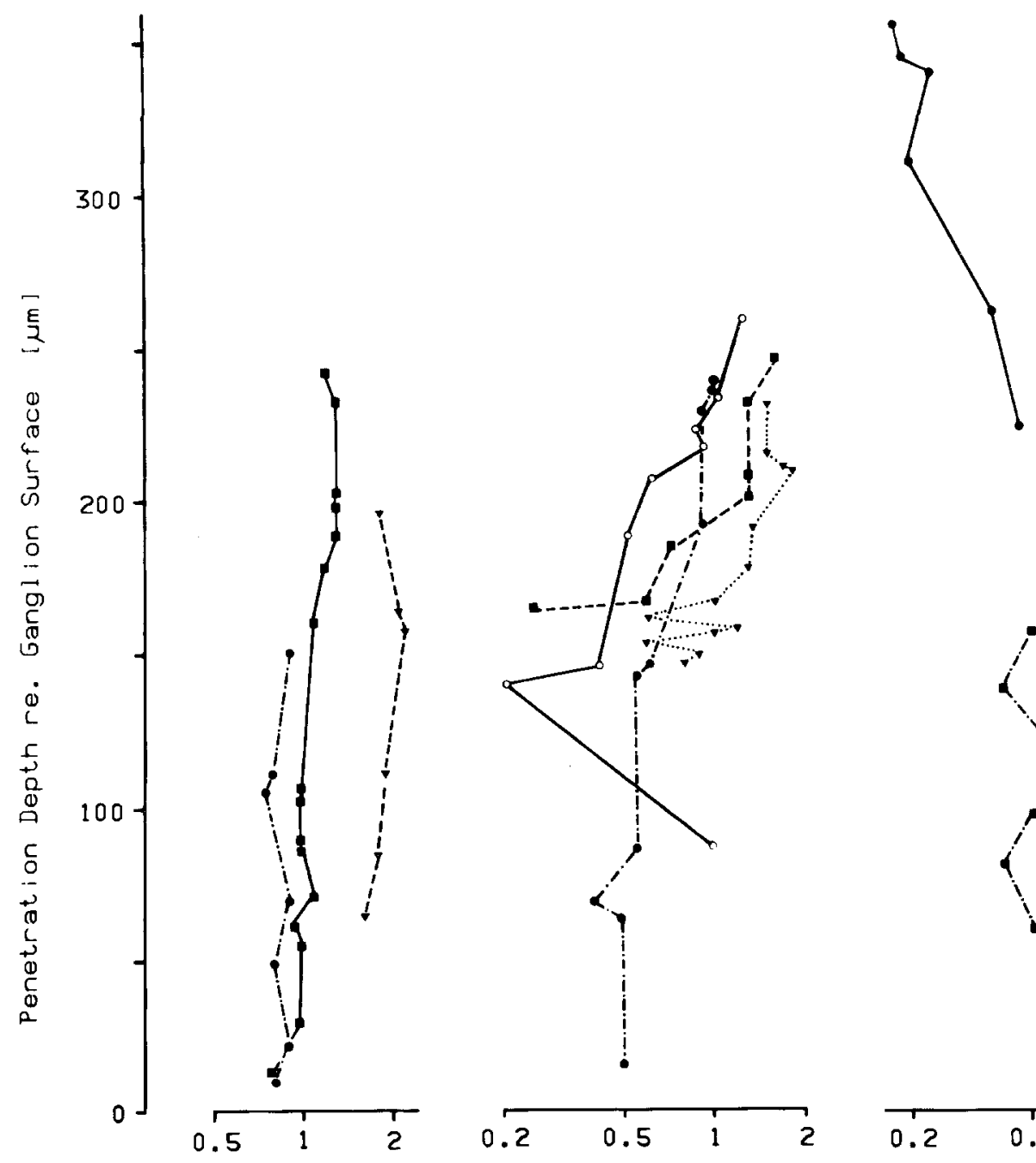

Characteristic Frequency [ $\mathrm{kHz}]$

Fig. 19. The systematic change of $\mathrm{CF}$ with electrode penetration depth is an indication of a tonotopic arrangement of auditory cells in the cochlear ganglion. Ten different penetrations are presented, arranged according to the tendency of the $\mathrm{CF}$ change (left: relatively constant $\mathrm{CF}$; centre: rising $\mathrm{CF}$; right: falling $\mathrm{CF}$ ). Points on the curves represent $\mathrm{CFs}$ of single cells 


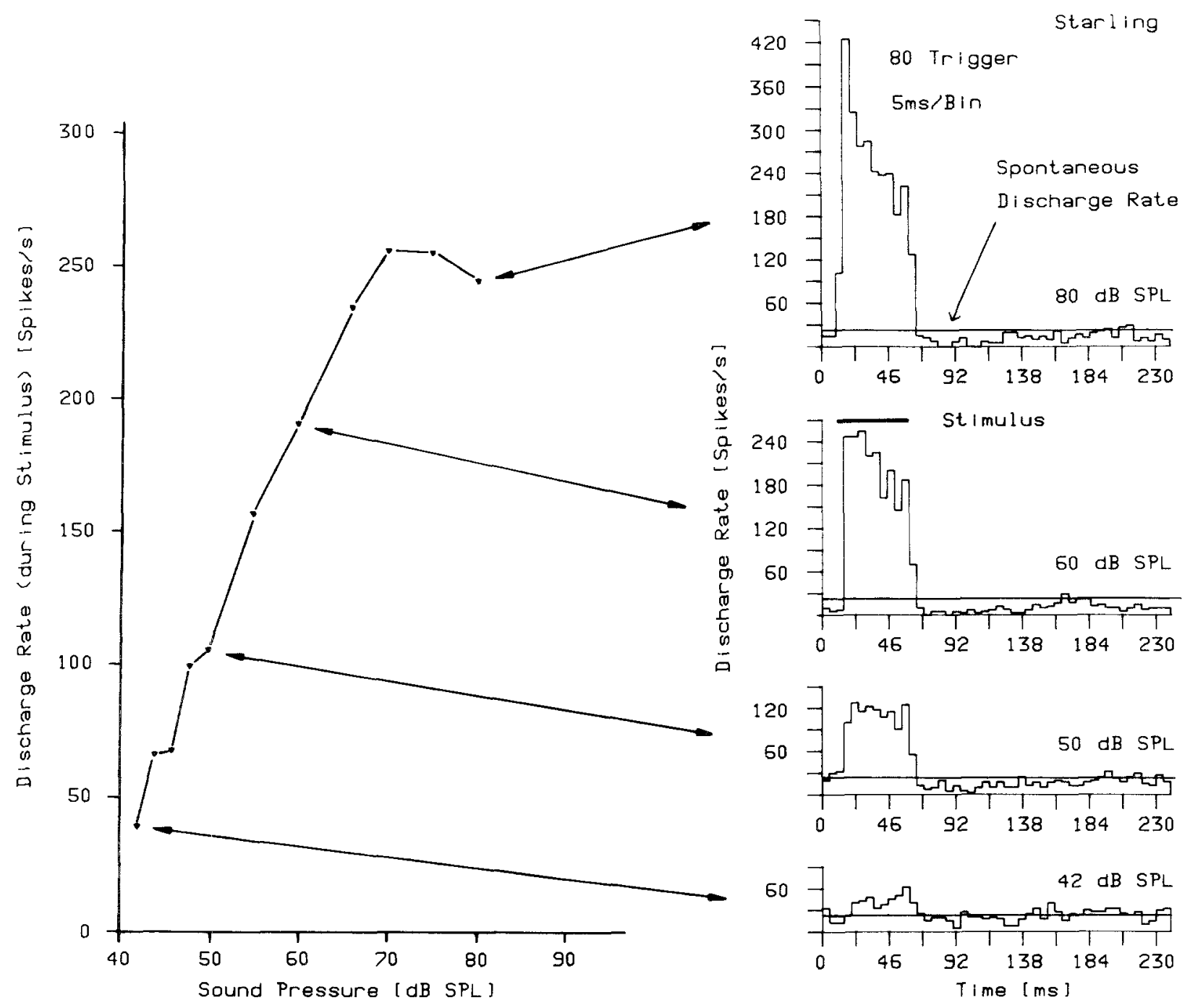

Fig. 20. Input-output function of a neurone stimulated with tone bursts of different intensities at the CF. PST histograms on the right illustrate response patterns at the four indicated (arrows) positions on the curve

cells showed a suppression of spontaneous activity. This suppression increased in strength and duration with increasing sound pressure level (Fig. 20). At saturation, some cells did not fully recover their spontaneous rate before the next tone $(200 \mathrm{~ms}$ interval). Thus, the dynamic ranges given below may be somewhat compressed due to inadequate recovery times. From the threshold, the discharge rate of cells increased mostly monotonically with increasing sound pressure (Fig. 20), often up to rates

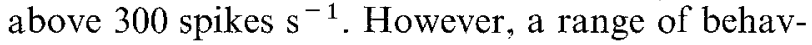
iours was present, some cells saturating between 100 and 150 spikes s $^{-1}$ (Fig. 21). It was not possible to correlate these differences with, e.g., threshold or sharpness of tuning. Similar ranges of saturation rates, albeit somewhat lower, were found with continuous tones. Dynamic ranges (threshold to saturation) for short duration tones for 18 cells lay rather evenly distributed betwen 10 and $50 \mathrm{~dB}$ (mean: $25 \mathrm{~dB}$ ). Cells with a narrow dynamic range showed a low saturation rate.

'Odd' responses. Several units exhibited response characteristics which have not been reported in responses of mammalian primary auditory neurones. In five cells, phase-coupling intervals were observed which represented intervals of only onethird of the stimulus period. In two of these cases, the cells had CFs of $0.9 \mathrm{kHz}$ and $0.7 \mathrm{kHz}$ and fired to an $0.3 \mathrm{kHz}$ stimulus with intervals which represented the CF-period better than the stimulus period. Spectral analysis of the stimulus demonstrated insufficient energy in the harmonics of the $0.3 \mathrm{kHz}$ stimulus to stimulate the cells at their CFs. Both cells were more sensitive to $0.3 \mathrm{kHz}$ than expected from a 'normal' tuning curve. One cell showed this behaviour at its CF and at all sound pressures used. 


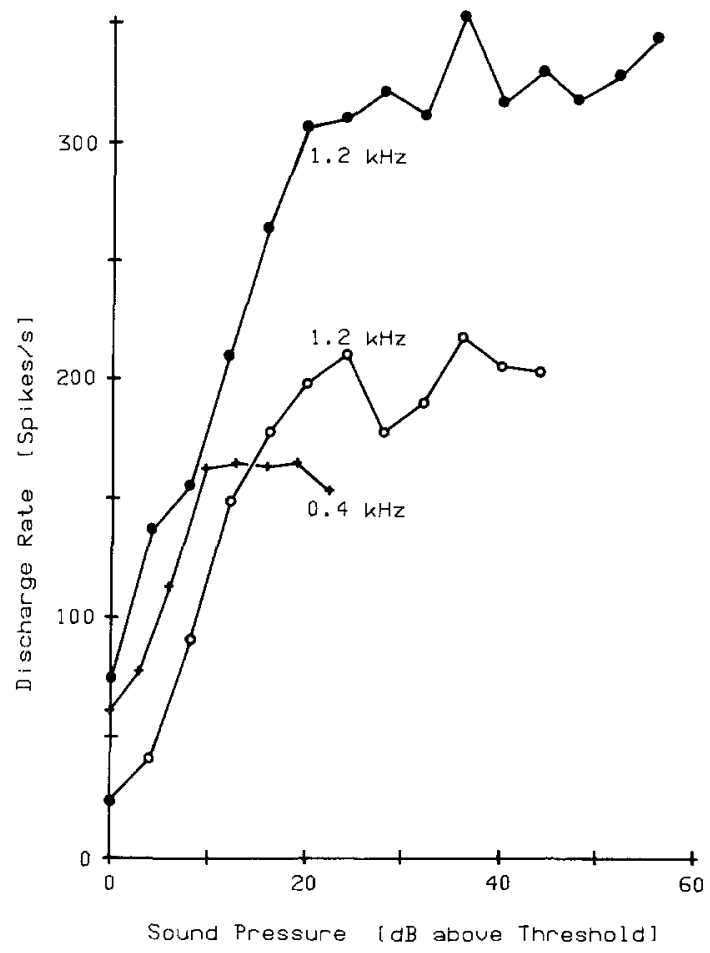

Fig. 21. Typical input-output functions for cochlear ganglion cells in the starling. Each cell was stimulated at the frequency indicated (the CF in each case)
In a number of other cases suppression of spontaneous activity during the stimulus was observed, followed by an 'off' response (Fig. 22). The 8 cells which were closely investigated all showed this effect, at least on the high-frequency end of the tuning curve. On-off responses ( 3 cells) were also observed, even at CF frequency. The cell in Fig. 23 shows this behaviour at a frequency below $\mathrm{CF}$ and at medium sound pressures. Additionally, raised firing activity long after the end of the stimulus (40-50 ms; 2 cells) and peculiar peaks in PST histograms with an interval of about $10 \mathrm{~ms}$ between them ( 2 cells) have been demonstrated.

None of these phenomena could be explained by resonances or other uncontrolled components in the stimulus situation or by stimulus distortion. As it was seldom possible to test cells under many different stimulus situations, the frequency of occurrence of these phenomena is certainly higher than is indicated here. However, the limited quantity of data does not yet permit a full description. Our impression during the last experiments was that suppression of spontaneous activity during a tone burst is especially common. This requires further investigation.

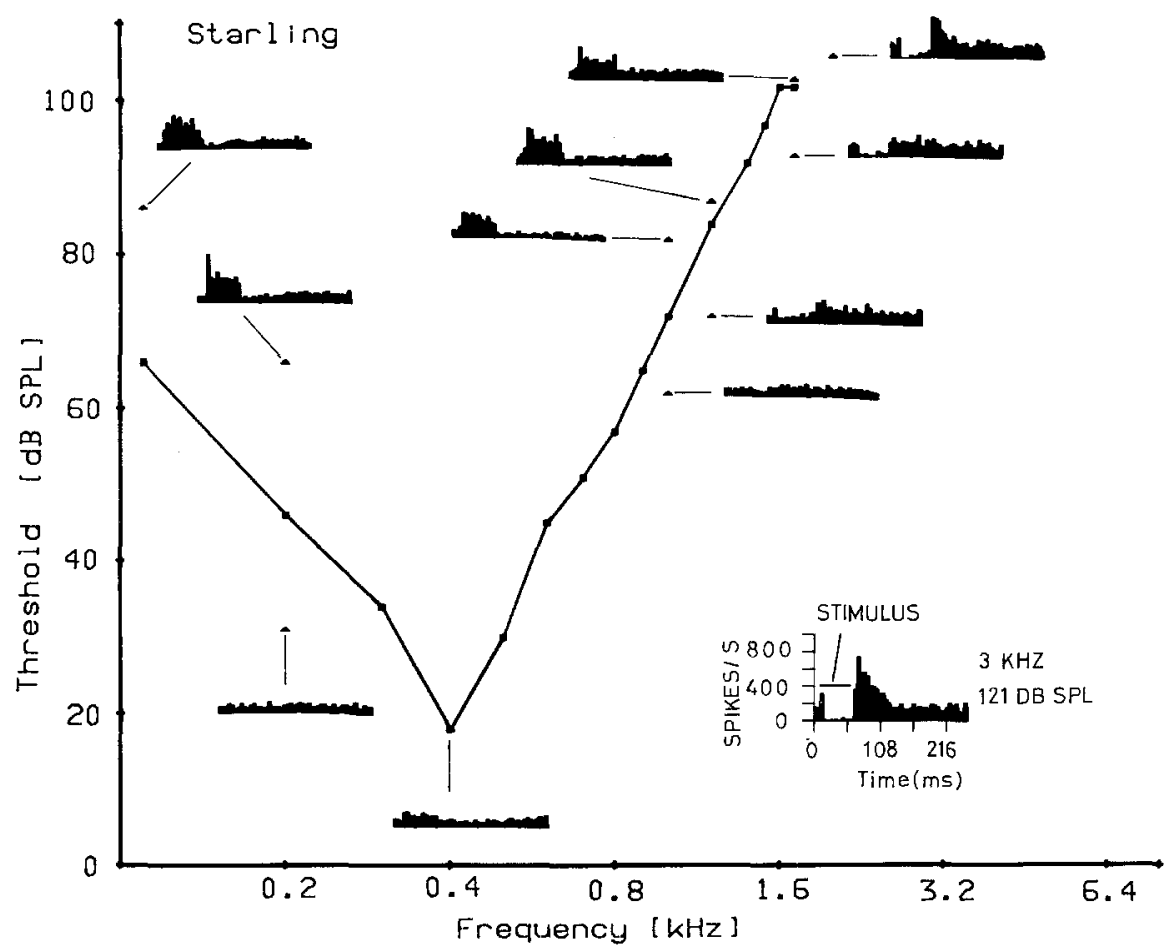

Fig. 22. Excitatory tuning curve of a cochlear ganglion cell. For this units, twelve PST histograms are shown at stimulus frequencies and sound pressures as indicated. The PST histogram on the lower right $(3 \mathrm{kHz}, 121 \mathrm{~dB}$ SPL) gives the scales for the time relationships of the stimulus. This histogram and the four histograms to the right of the high-frequency flank of the TC show primary suppression to the stimulus and an 'off' discharge 


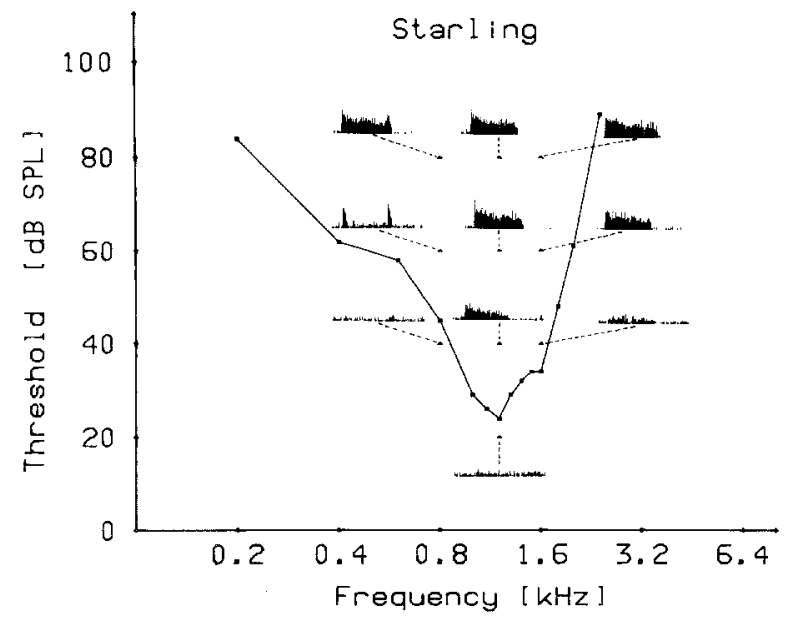

Fig. 23. Tuning curve of a cochlear ganglion cell and PST histograms of pure tone responses. Note the on-off response in the left column of histograms

\section{Discussion}

The surgical approach used here is a rapid method for exposing the cochlear ganglion in birds. The operation is much less traumatic than an approach to the nerve through the brain cavity and this preparation can provide very long recording times from single cells (more than $1 \mathrm{~h}$ ). The method does, however, have two disadvantages. Firstly, unless precautions are taken to supply the bird with sufficient fluids, the perilymph level in the opened scala tympani can fall rapidly within a relatively short time period. Secondly, the approach angle of the electrode is such that middle- and low-frequencyCF cells and lagenar cells lie preferentially in the recording path. Even with careful selection of the electrode track, it is difficult to record from many high-CF cells. Additionally, these cells presumably innervate the basal region of the cochlea which lies nearest the opening in scala tympani and thus is more exposed to mechanical trauma during the operation and more affected by a fall in perilymph level than the apical region. When a systematic sampling of the ganglion is not required, however, this method is advantageous for recording from the auditory nerve in birds.

The present results have implications for the functional significance of the anatomical organization of the avian cochlea. Therefore a brief description of the salient points follows. There exist comparatively few recent descriptions of the anatomy of the bird's ear (Chandler 1984a, b; von Duering et al. 1983; Firbas and Mueller 1983; Rosenhall 1971; Smith 1981; Takasaka and Smith 1971; Tanaka and Smith 1978) The basilar papilla in birds is several millimeters long, slightly curved and ta- pered. In different species, there are two or more hair-cell types - tall, intermediate and short, which differ not only in height, but also in aspects of fine structure and innervation. Along the basilar membrane, there is a gradient in length of the stereovillar bundles (Tanaka and Smith 1978). The term 'stereovilli' has been suggested by U. Thurm and co-workers and is adopted here as a better alternative to microvilli (they are not small) or stereocilia (they are not cilia). All stereovillar bundles have close contact to a thick tectorial membrane. In contrast to the mammal's cochlea, many hair cells (14-54 in the pigeon), appear in a given transverse section of the basilar papilla. Both tall- and short-hair-cell groups show axosomatic synapses between hair cells and both afferent and efferent nerve fibres. There are about $12 \%$ more short than tall hair cells.

One tall ('inner') hair cell receives between 1 and 4 afferent nerve fibres (von Duering et al. 1983), showing the highest innervation density in the most superior (inner) portion of the papilla. Tall hair cells near the zone of transition to short ('outer') hair cells receive only one afferent fibre. One fibre commonly has synaptic contact with one or two neighbouring tall hair cells. In contrast, up to 6 short hair cells (on average three) share one afferent fibre. On the basis of average innervation densities, von Duering calculates that only $18 \%$ of afferent fibres in the starling innervate short hair cells. Whereas tall hair cells show more numerous, larger afferent endings than do short hair cells, the situation with regard to efferent endings is just the reverse. Chandler (1984a), Firbas and Mueller (1983), Takasaka and Smith (1971) and Tanaka and Smith (1978) report similar findings for the cochlea of different species.

Spontaneous activity. The presence of both auditory and non-auditory neurones in the cochlear ganglion of birds would indicate the lagena as the site of origin of the non-auditory units. It is, however, difficult to exactly delimit these populations, as there are certainly some auditory units whose $\mathrm{CF}$ falls below $100 \mathrm{~Hz}$ and therefore could not be reliably stimulated with our equipment. A similar observation has been reported for the caiman (Klinke and Pause 1980). Thus, the origin of these verylow-frequency responses remains to be clarified. Experiments with direct stimulation of the lagena (Oeckinghaus, in preparation) were consistent with these ideas, but also inconclusive. The information provided by the vestibular components of the inner ear concerning static components (gravity) and dynamic components (motion) would be optimally 
encoded by a combination of regularly- and irregularly-discharging units. It is conceivable that the latter grouping could show a continuum of responses to motion, vibration and low-frequency sound. This remains to be investigated in the case of the lagena.

In the present study, the variety of TIH patterns of cochlear and lagenar units strongly resembles the types found in the whole eighth nerve of the cat (Walsh et al. 1972). This suggests the existence of common types of innervation patterns and spontaneous-discharge generator mechanisms. The irregular activity patterns in the spontaneous firing of auditory-nerve fibres in the starling conforms to the patterns universally seen in other birds, in mammals and in reptiles (see e.g., Manley 1980; Manley and Robertson 1976; Sachs et al. 1980 a, b; Walsh et al. 1972). The spontaneous rate varies from unit to unit and, to some extent, with the condition of the animal. In the caiman, and presumably in other reptiles, the spontaneous rate is temperature-dependent (Klinke and Smolders 1977).

In the guinea pig, the rate also depends on the metabolic condition of the animal (Manley and Robertson 1976). When metabolically-impaired cells (whose thresholds exceeded $50 \mathrm{~dB}$ SPL) were excluded from the analysis, the mean rate in the guinea pig was 61 spikes $\mathrm{s}^{-1}$ instead of 45 spikes $\mathrm{s}^{-1}$. For cells with rate thresholds below $50 \mathrm{~dB}$ SPL, there was no correlation between spontaneous rate and threshold (Manley and Robertson 1976). It appears that in the starling the situation is similar, except that we differentiated here between sensitive birds and birds where all thresholds lay above $50 \mathrm{~dB}$ SPL. The result of this differentiation gives a 'normal' mean spontaneous rate of 48 spikes $\mathrm{s}^{-1}$ instead of 45 spikes $\mathrm{s}^{-1}$. The distribution is unimodal (Fig. $3 \mathrm{a}$ ).

In the cat, afferents have a mean spontaneous rate of 30 spikes s $^{-1}$ (Sachs et al. 1974). Both cat and guinea pig show a bimodal distribution of rates. Sachs et al. (1980a) report for both the pigeon and the redwing blackbird mean spontaneous

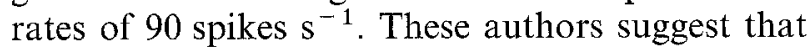
the fact that these rates (and the rates of soundinduced activity) exceed those seen in mammals may be explained by the higher body temperature and higher metabolic rate in the bird. In the starling, however, the rates of spontaneous activity are not substantially higher than in cat and guinea pig. It is by no means clear why the spontaneous rate in the starling should be half that seen in the pigeon and redwing blackbird. Possible effects of different anaesthetics are unlikely, as Sachs et al. also found normal rates in cats anaesthetized with chloralose. We have not attempted recordings in these other species using our technique. In contrast to this dramatic difference in spontaneous rates between starling on the one hand and pigeon or redwing blackbird on the other, the rates of saturated activity in response to tones are very similar in all three species (see below).

Among the vertebrates, it appears as if there are two types of distribution of rates of spontaneous activity: unimodal and bimodal. A unimodal distribution is shown by birds (Sachs et al. 1974, $1980 \mathrm{a}$, and Fig. 3 in this paper) and some reptiles (Manley 1981). A bimodal distribution is shown by mammals (Evans 1972; Kiang 1965; Kim and Molnar 1979; Liberman 1978; Manley and Robertson 1976) and by the caiman (Klinke and Pause 1980). It is curious that the distributions in bird and caiman are so different, for the cochleae resemble each other strongly. This raises, of course, the question as to the origin of spontaneous activity.

It is generally agreed that most spontaneous activity is not sound-evoked (see e.g., discussion in Sachs et al. 1980a). This is certainly the case in cells with relatively poor sensitivity that were recorded in acoustically well-shielded chambers. There are two possible sites of origin of the spontaneous activity. The first possibility assumes that the hair-cell presynaptic membrane randomly releases transmitter vesicles with a rate specific for each synapse (Walsh et al. 1972). This bombardment of the afferent fibre produces activity in the absence of stimuli. Alternatively, 'noise' in the membrane potential of the afferent dendrite could also potentially produce such activity (Weiss 1966).

Manley and Robertson (1976) studied the effects of hypoxia on spontaneous and sound-evoked activity in the guinea-pig auditory nerve. Although hypoxia sometimes had a differential effect on sound threshold and on spontaneous activity, it was not possible on the basis of these experiments to clearly differentiate between these two hypotheses as to the origin of spontaneous activity. Geisler (1981) has suggested an explanation for a bimodal distribution of rates of spontaneous activity. This hypothesis is attractive but only if the spontaneous activity has as its origin the random output of transmitter from the hair cell. According to this hypothesis, many afferent fibres discharge in response to the release of single transmitter packages. Other fibres, however, have a higher threshold and require at least two transmitter packages almost simultaneously in order to reach firing threshold. These latter cells form the population 
of low-spontaneous-rate units, as the congruence of two transmitter packets would occur less frequently. Thus, simply by assuming threshold differences of afferent endings, the bimodal distribution of spontaneous rates can be explained. Of course, a unimodal rate distribution would indicate that all cells possess roughly equivalent firing thresholds. As it is relatively easy to imagine that such threshold shifts could occur in the course of evolution without any structural changes, it may not after all be so surprising that, in spite of structural similarities, the distribution of rates in caiman is bimodal and in birds it is unimodal.

It should also be noted here that the hypothesis that spontaneous activity arises on the presynaptic side of the hair-cell synapse through random release of transmitter is also strengthened by the finding of preferred intervals as reported in this paper. The most reasonable explanation of this activity is in membrane-potential oscillations in the hair cell itself, activity which is then reflected in the afferent-fibre discharge pattern (see below).

In both the guinea pig (Manley and Robertson 1976) and the starling, the discharge rate of spontaneous activity of units suspected of being metabolically impaired was on average lower than in normal units. It is interesting to note, however, that in all cases the pattern of interval distributions was quite normal for that lower rate. This suggests that the mechanism which produces the random transmitter output (hair-cell membrane noise?) is independent of the mechanism which determines the rate (hair-cell membrane 'resting' potential?).

With regard to the pattern of interval distribution, a problem arises when a nerve fibre contacts more than one hair cell. Whereas for mammals it is relatively certain that activity in the auditory nerve only arises from fibres contacting only one inner hair cell (see Manley 1983 for review and new evidence in Robertson 1984), it appears that most bird fibres innervate more than one hair cell. In a theoretical study, Ehrenberger (1976) demonstrated that combining random inputs from hair cells on a single nerve fibre changed the resulting pattern of activity. With an increasing number of hair-cell inputs, the resulting fibre activity became more regular. With input from about 20 hair cells or synapses, the activity was quite regular, as seen here in some lagenar cells. If these principles can be applied to auditory-nerve fibres, it might be expected that auditory fibres which innervate several hair cells, as for example those innervating short hair cells in birds, would have somewhat longer modes than other cells. The data here do not indicate any bimodal or multimodal distribution of modes of TIH of spontaneous activity (Fig. 6). Whereas in comparison to the guinea pig (Manley and Robertson 1976; Fig. 5b), the modes in the starling are on average shorter, the spread of values is not obviously greater. We thus conclude that either Ehrenberg's hypothesis does not apply here or the number of innervated hair cells is too small to significantly affect the discharge pattern. It may, of course, also be the case that for some reason we only recorded activity originating from tall hair cells, where the fibres only innervate one or two hair cells (von Duering et al. 1983).

Modes reported for the caiman (only for units with rates above 8 spikes $\mathrm{s}^{-1}$ ) range up to $9.5 \mathrm{~ms}$. This large spread appears not simply to be due to lower spontaneous rates in the caiman, as the mode, e.g., for a unit with the relatively high rate of 65 spikes s$^{-1}$ is reported as $6 \mathrm{~ms}$. This exceeds all mode lengths found in the starling. The mode distribution and bimodal rate distribution in caiman may both point to a substantial difference in the origin of spontaneous activity as compared to the starling.

Preferred intervals in spontaneous activity. This phenomenon was first reported by Manley (1979) in data from the starling and the tokay gecko. Manley also reviewed the arguments against the possibility that preferred intervals arise through inadvertent noise stimulation of hair cells. Subsequently, similar phenomena have been reported in auditory nerve fibres of the red-eared turtle (Crawford and Fettiplace 1980) and the membrane noise of single hair cells of this turtle has been shown to preferentially contain energy in the region of the CF (Crawford and Fettiplace 1981 a, b). These data taken together not only strengthen the impression that spontaneous activity of auditorynerve fibres has its origin on the presynaptic side of the hair cell, they also indicate that the preferred intervals are a reflection of a frequency selectivity present in the unstimulated hair cell. This may be due to an electrical filtering of membrane noise by the hair-cell membrane. Such preferred intervals have never been reported in mammals and the possibility that they may have simply been overlooked has been checked by careful analysis of data from low-CF cells (Geisler, personal communication).

The data on preferred intervals reported here for cells with $\mathrm{CF}$ below $1.6 \mathrm{kHz}$ encompass three new findings (see also Manley and Gleich 1984). Firstly, an analysis of the 'goodness-of-fit' between the 'basic interval' of an individual cell (see Results, Fig. 11) and the CF-period revealed that, contrary to Manley's earlier impression based on 
fewer data, the preferred intervals are not exactly multiples of the CF-period. They are, on average, approximately $15 \%$ longer, so that it appears that, if these intervals reflect a filter in the hair cell, the hair cells are 'tuned' at rest to a frequency $15 \%$ lower than the $\mathrm{CF}$ might suggest.

Secondly, the mode of the TIH of lower-CF cells is also a preferred interval in the sense of bearing a fixed relationship to the cell's CF, even though further peaks at multiples of the mode's interval do not appear. Thus, all lower-CF cells have a pattern of spontaneous activity which reflects their tuning properties. In these cells, either the mode interval alone or the mode and "basic interval' indicate a natural 'resonance', probably of the hair cell(s) at a frequency on average 15\% lower than would be expected from the CF derived from tone stimuli. This fact alone makes it extremely unlikely that preferred intervals are due to inadvertent acoustic stimulation or even to 'body noise', as there is no reason why the best response frequency in this case should differ from that in response to tonal stimuli. Neither can this systematic difference as compared to tonal-CF be explained by possible sources of scatter in the data, such as inaccurate determination of the tonal CFs or inadequate resolution of the computer analysis. The lack of correspondence between the cells' CFs and their spontaneous oscillations is curious, as one would expect the frequency of most sensitive response to a tone to be in conformity with the frequency of natural 'resonance' of the cell. Why this is not so will only be explicable when we understand the origins of both of these selectivity mechanisms.

Thirdly, the dead times of TIH are related to the modes, being on average $30 \%$ shorter. This influence of the cell's tuning properties (for lowerCF cells) on both mode and dead time are partially responsible for the fact that TIH modes in the starling are, on average, substantially shorter than those in the guinea pig and also that the dead times show a compact distribution at very short values (Fig. 8b). Indeed, when units showing a 'shoulder' in their TIH are ignored, all modes of TIH are shorter than $2.5 \mathrm{~ms}$, thus being very much shorter than in mammals. The origin of a 'shoulder' in a TIH is unknown. In such a TIH, the mode is abnormally long and no longer near the CF-period, but double this length. For some reason, there is a shift in the interval frequencies in these units, which form about $20 \%$ of the unit population studied here. Whether this behaviour has anything to do with the innervation pattern remains to be investigated.
Tone-evoked discharge patterns. The finding of a tonotopic organization in the cochlear ganglion was, of course, expected in view of the organization of the papilla basilaris and the tonotopic organization of the cochlear nucleus (Konishi 1970) and forebrain (Leppelsack 1978). The expectation of finding low-CF fibres at the wider distal end of the cochlea is fully supported by the data of the present study (Fig. 2). That lagenar (non-auditory) fibres were found predominantly as neighbours of lower-CF fibres supports the contention that these frequencies are analysed in the distal portion of the basilar papilla (Fig. 2, Boord and Rasmussen 1963). Additionally, recording from fibre bundles near the basilar membrane demonstrated consistent $\mathrm{CFs}$ in single penetrations and a correlation between $\mathrm{CF}$ and location. However, such penetrations were infrequent and in different animals, so that no exact map of the basilar papilla can be presented. This distribution of CFs is also consistent with the noise-damage data of Rebillard et al. (1982).

Studies of innervation density (e.g., Takasaka and Smith 1971) indicate that the lower-frequency area of the cochlea receives twice as many afferent fibres as the higher-frequency area. In the cochlear nucleus, Konishi (1970), using a technique for systematically sampling cells in different areas, found many more cells responding to the middle-CF range as to both extremes. These findings, combined with potential damage to the base of the cochlea during surgery explain the fact that high$\mathrm{CF}$ fibres were infrequently encountered in this study. Whereas Konishi (1970) reports a CF-range of 0.25 to $6.25 \mathrm{kHz}$ in the cochlear nucleus of the starling, we report a range of 0.15 to $4.2 \mathrm{kHz}$. For these reasons, our data are not suited to constructing a histogram of CF distribution and cell numbers.

Our lowest thresholds (Fig. 18) lie significantly higher than those shown by Konishi (1970: rateincrease criterium) and by behavioural studies (Kuhn et al. 1980). There are a number of reasons for this. Firstly, we altered the normal acoustical conditions of the eardrum, in that the middle ear lay opened under the free-field stimulation conditions used here. In the tokay gecko, closed-acoustical-system recordings are about $10 \mathrm{~dB}$ more sensitive than free field with opened middle ear (Manley 1981). Secondly, the tones used in this study were very short $(50 \mathrm{~ms})$. Psychophysical studies of bird and mammal hearing show an improvement in threshold of $6 \mathrm{~dB}$ by an increase of tone length from 50 to $200 \mathrm{~ms}$ (Dooling 1979). Thirdly, our preliminary findings also indicate substantially 
lower thresholds for phase-locking than for the rate-increase criteria used in collecting the data reported here.

The wide range of thresholds we report (up to $60 \mathrm{~dB}$ at one frequency) does not seem to be artefactual. Liberman (1978) reports a threshold range of up to $50 \mathrm{~dB}$ for the cat, a range also observed in the caiman (Klinke and Pause 1980). In a few cases, we recorded early in the experiment from insensitive units and, at the same CF, at the end of the experiment from a sensitive unit. Thus, there is no reason to regard this threshold spread as indicative of pathological conditions. General effects of the depth of anaesthesia were not observed.

Tuning curves in the starling were not consistently asymmetrical (Figs. 13 to 16). Sachs et al. (1974) provide no detail for the pigeon, but observe that the tuning curves are $\mathrm{V}$-shaped and similar to those in the cat cochlea. A perusal of their figures, however, indicates that the tuning curves of units with CF below $1.5 \mathrm{kHz}$ have steeper slopes on the low-frequency side. Certainly, no low-frequency 'tails' as observed in mammalian units of $\mathrm{CF}$ above $1 \mathrm{kHz}$ were observed. Our data indicate that for the starling, the tuning curves have, on average, slopes of equal steepness on the high- and low-frequency side (Fig. 14a). The relationship is not consistent across CF, however. Lower-CF units have tuning curves steeper on the low-frequency slope, while higher-CF fibres have the reverse (Fig. 15a). Professor Bob Harrison, Toronto, Canada, has kindly provided us with data from the guinea pig in a CF-range corresponding to that found in the starling. This comparison is important, because there is no clarity in the literature with regard to tuning curve shape and symmetry in birds. Our observations are clearly different to the data from the guinea pig (Figs. 14b, 15b). In the guinea pig, only $12 \%$ of fibres have a steeper low-frequency slope and these fibres are evenly distributed throughout the CF-range. The wellknown asymmetry of mammalian auditory-nerve fibres apparently extends down to very low CFs. Thus, there is an important qualitative difference between tuning-curve shapes in the starling and those in the guinea pig.

Curiously, the tuning curves of caiman, with a cochlear structure resembling that of birds, are reported to be asymmetrical (Klinke and Pause 1980) although the range of slopes on the highfrequency side (30 to $180 \mathrm{~dB}$ /octave) are little higher than on the low-frequency side $(10$ to $150 \mathrm{~dB} /$ octave). Until we know what factors determine these tuning-curve shapes, it is difficult to estimate the significance of these differences. For this reason, it is also unclear as to why the maximal highfrequency slope of starling tuning curves increases consistently with CF (Fig. 16a) whereas the lowfrequency slope shows a less consistent increase (Fig. 16b).

There is good agreement between our data concerning $Q_{10 \mathrm{~dB}}$-values for tuning curves in the starling and that reported for pigeon and redwing blackbird nerve fibres (Sachs et al. 1978; Sachs and Sinnott 1978). Q-values for starling fibres match or exceed those for the guinea pig (see e.g., Fig. $17 \mathrm{a}$ and $\mathrm{b}$ ). Thus, the peripheral auditory system of the starling is as frequency selective as that of an unspecialized mammal. The mean Q-value rises with frequency, which is consistent with the findings of Saunders et al. (1978) that psychophysical tuning curves for the parakeet are sharpest above $2 \mathrm{kHz}$. They and Dooling (1979) report smaller critical ratios and critical bands in birds above $1.5 \mathrm{kHz}$. However, the birds' performance in these respects is inferior to that of mammals, so that equivalent sharpness of tuning curves cannot mean equivalent performance in discrimination tests, unless such tests are, for other reasons, more difficult to conduct with birds.

The phasic-tonic PST-response patterns shown here strongly resemble the 'primary-like' pattern of mammalian auditory-nerve fibres (Fig. 20). The maximal discharge rates in cats $\left(190\right.$ spikes $\mathrm{s}^{-1}$, Sachs et al. 1978) is exceeded by the rates in the starling (tonic rates often exceeded 300 spikes s$^{-1}$ and phasic components initially exceeded 450 spikes $\mathrm{s}^{-1}$ ). Similar data have been demonstrated for other bird species (Sachs et al. 1978). This vigorous discharge activity parallels the higher spontaneous rates of birds, but its significance is not yet understood. An effect of temperature is unlikely, as some birds apparently show substantially higher spontaneous rates (Sachs et al. 1980 a). Certainly, these high activity bursts in response to louder tones suppress the spontaneous activity following the tones, often down to zero, followed by a recovery time $4-5$ times longer than the tone burst. It should be noted that, as we used a 1:4 (tone:silence) duty cycle, the silent intervals were probably too short for full recovery from high-intensity tones. This may lead to an underestimation of maximum potential discharge rates and a compression of dynamic range.

We do not have sufficient data on dynamic ranges to comment on the "sloping saturations" shown by Sachs et al. (1980a) for their bird and mammal data. Our data generally showed a clear break in the slope of discharge-rate increase 
(Fig. 21), so that it was relatively easy to determine the primary dynamic range of each unit. This range (10 to $50 \mathrm{~dB}$; mean $25 \mathrm{~dB}$ ) exceeds that seen in the caiman (20 to $40 \mathrm{~dB}$ ) as do the corresponding saturation discharge rates (caiman: 40-200 spikes $\mathrm{s}^{-1}$; Klinke and Pause 1980). However, caiman rate-intensity functions were nonmonotonic, decreasing greatly at higher intensities. Although we have not observed this phenomenon, our recorded sound-pressure ranges were frequently not as large as would be necessary to test this adequately. This, and the steepness of intensity functions at several frequencies for each unit, must be the subject of further study.

Sachs and Sinnott (1978) occasionally observed weak suppression to single tones in the redwing blackbird. Inhibitory side-bands occur regularly in cochlear-nucleus units (Hotta 1971; Sachs and Sinnott 1978; Sachs et al. 1978). As can be seen in Fig. 22, we have observed primary suppression in starling nerve fibres. As the strategy necessary to efficiently explore this phenomenon differed from the data-collection methods employed in the current investigation, we reserve detailed discussion to a later date. Preliminary data, however, indicate this phenomenon to be more common than we suspected. It is conceivable that some part of the observed suppressive side-bands at the cochlear nucleus level is already present in the discharge patterns of cochlear nerve fibres to single tones. As the tectorial membrane is suspected of playing a role in two-tone suppression at the periphery (Manley 1981), primary suppression in birds may be traceable to a firm link between all hair cells and the tectorial membrane. Inner hair cells of mammals probably have no such connection. Further investigation of other unusual responses such as 'on-off' PSTs (Fig. 23) may allow more general statements to be made.

The meagre information on afferent fibre branching patterns in the bird cochlea precludes detailed interpretation of some of the above data. It appears as if fibres only innervate a narrow band of hair cells across the papilla (Chandler 1984a; Takasaka and Smith 1971), which may partly explain the good frequency selectivity of primary auditory units. It appears that the short hair cells receive about $18 \%$ of afferent fibres and that each of these fibres innervates up to 6 short hair cells. Fibres to tall hair cells innervate only one or two sensory cells (von Duering et al. 1983). From this information, one might expect to find two fibre populations (as also long sought-for in mammals). We have no discharge patterns which are firm candidates for separating such populations. In the cai- man, where a similar innervation pattern exists (von Duering et al. 1974), it was also not possible to distinguish two fibre populations in response to standard stimuli (Klinke and Pause 1980). It will be necessary here, as in mammals (e.g., Robertson 1984) to use fibre-tracing techniques to determine the site of origin of specific response patterns. Thus, it is not possible to discuss the possibility that any interactions occur between populations of hair cells in the papilla, as now seems highly likely in the organ of Corti of mammals. The solution to these problems must await further data.

Acknowledgements. We thank Christine Koeppl for typing and Dan Margoliash for commenting on the manuscript. We also thank Gabi Schwabedissen, Birgit Seibel and Monika Vogt for technical assistance. Supported by the Deutsche Forschungsgemeinschaft within the programmes of the SFBs 50,114 and 204.

\section{References}

Boord RL, Rasmussen GL (1963) Projection of the cochlear and lagenar nerves on the cochlear nuclei of the pigeon. J Comp Neurol 120:463-473

Chandler JP (1984a) Light and electron microscopic studies of the basilar papilla in the duck, Anas platyrhynchos. I. The hatchling. J Comp Neurol 222:506-522

Chandler JP (1984b) Light and electron microscopic studies of the basilar papilla in the duck, Anas platyrhynchos. II. Embryonic development. J Comp Neurol 222:523-542

Crawford AC, Fettiplace RR (1980) The frequency selectivity of auditory nerve fibres and hair cells in the cochlea of the turtle. J Physiol 306:79-125

Crawford AC, Fettiplace RR (1981a) An electrical tuning mechanism in turtle cochlear hair cells. J Physiol 312:377-412

Crawford AC, Fettiplace RR (1981b) Non-linearities in the responses of turtle hair cells. J Physiol 315:317-338

Dooling RJ (1979) Temporal summation of pure tones in birds. J Acoust Soc Am 65:1058-1060

Duering M von, Karduck A, Richter H-G (1974) The fine structure of the inner ear in Caiman crocodilus. Z Anat EntwicklGesch 145:41-65

Duering M von, Andres KH, Simon K (1983) The comparative anatomy of the basilar papillae in birds. Int Symp on Vertebrate Morphol

Ehrenberger K (1976) Input-output relations in primary vestibular neurones. 13th Workshop on Inner Ear Biology, Düsseldorf

Evans EF (1972) The frequency response and other properties of single fibres in the guinea-pig auditory nerve. J Physiol 226:263-287

Firbas W, Mueller G (1983) The efferent innervation of the avian cochlea. Hearing Res 10:109-116

Geisler CD (1981) A model for discharge patterns of primary auditory-nerve fibres. Brain Res 212:198-201

Gross NB, Anderson DJ (1976) Single unit responses recorded from the first order neuron of the pigeon auditory system. Brain Res 101:209-222

Hotta $T$ (1971) Unit responses from the nucleus angularis in the pigeon's medulla. Comp Biochem Physiol 40A:415-424

Kiang NYS (1965) Discharge patterns of single fibres in the cat's auditory nerve. MIT Press, Cambridge, Mass 
Kim DO, Molnar CE (1979) A population study of cochlear nerve fibres: comparison of spatial distributions of averagerate and phase-locking measures of responses to single tones. J Neurophysiol 42:16-30

Klinke R, Pause M (1980) Discharge properties of primary auditory fibres in Caiman crocodilus; comparisons and contrasts to the mammalian auditory nerve. Exp Brain Res $38: 137-150$

Klinke R, Smolders J (1977) Effect of temperature shift on tuning properties. Addendum to: Klinke R, Pause M (1977) The performance of a primitive hearing organ of the cochlea type: primary fibre studies in the caiman. In: Evans EF, Wilson JP (eds) Psychophysics and physiology of hearing. Academic Press, London, pp 109-111

Konishi M (1970) Comparative neurophysiological studies of hearing and vocalizations in songbirds. Z Vergl Physiol $66: 257-272$

Kuhn A, Leppelsack H-J, Schwartzkopff J (1980) Measurement of frequency discrimination in the starling (Sturnus vulgaris) by conditioning of heart rate. Naturwissenschaften 67:102-103

Leppelsack H-J (1978) Unit responses to species-specific sounds in auditory forebrain centers of birds. Fed Proc $37: 2336-2341$

Liberman MC (1978) Auditory-nerve responses from cats raised in a low-noise chamber. J Acoust Soc Am 63:442-455

Manley GA (1973) A review of some current concepts of the functional evolution of the ear in terrestrial vertebrates. Evolution 26:608-621

Manley GA (1979) Preferred intervals in the spontaneous activity of primary auditory neurones. Naturwissenschaften 66:582

Manley GA (1980) Response characteristics of auditory neurones in the cochlear ganglion of the starling. Acta XVII Congr Int Ornithol 697-700

Manley GA (1981) A review of the auditory physiology of reptiles. Progr Sensory Physiol 2:49-134

Manley GA (1983) Auditory nerve fibre activity in mammals. In: Lewis B (ed) Bioacoustics. Springer, Berlin Heidelberg New York Tokyo, pp 207-232

Manley GA, Gleich O (1984) Avian primary auditory neurones: the relationship between characteristic frequency and preferred intervals. Naturwissenschaften 71:592-594

Manley GA, Leppelsack H-J (1977) Preliminary data on activity patterns of cochlear ganglion neurones in the starling. In: Portman M, Aaron J-M (eds) Inner ear biology - XIVth workshop. INSERM Paris, pp 127-136

Manley GA, Robertson D (1976) Analysis of spontaneous activity of auditory neurones in the spiral ganglion of the guinea-pig cochlea. J Physiol 258:323-336

Miller MR (1980) The reptilian cochlear duct. In: Popper AN, Fay RR (eds) Comparative studies of hearing in vertebrates. Springer, Berlin Heidelberg New York pp 169-204

Rebillard M, Pujol R (1983) Innervation of the chicken basilar papilla during its development. Acta Otolaryngol (Stockh) 96:379-388

Rebillard G, Ryals BM, Rubel EW (1982) Relationship between hair cell loss on the chick basilar papilla and threshold shift after acoustic overstimulation. Hearing Res 8:77-81
Robertson D (1984) Horseradish peroxidase injection of physiologically characterized afferent and efferent neurones in the guinea-pig spiral ganglion. Hearing Res 15:113-121

Rosenhall U (1971) Morphological patterns of the organ of Corti in birds. Arch Otorhinolaryngol 200:43-63

Sachs L (1970) Statistische Methoden. Springer, Berlin Heidelberg New York

Sachs MB, O'Connell NA (1983) Frequency analysis in the central auditory system of non-mammalian vertebrates. In : Lewis B (ed) Bioacoustics - a comparative approach. Academic Press, London, pp 283-310

Sachs MB, Sinnott JM (1978) Responses to tones of single cells in nucleus magnocellularis and nucleus angularis of the redwing blackbird (Agelaius phoeniceus). $\mathrm{J}$ Comp Physiol 126:347-361

Sachs MB, Young ED, Lewis RH (1974) Discharge patterns of single fibres in the pigeon auditory nerve. Brain Res $70: 431-447$

Sachs MB, Sinnott JM, Hienz RD (1978) Behavioral and physiological studies of hearing in birds. Fed Proc 37:2329-2335

Sachs MB, Woolf NK, Sinnott JM (1980a) Response properties of neurones in the avian auditory system: comparisons with mammalian homologues and consideration of the neural encoding of complex stimuli. In: Popper AN, Fay RR (eds) Comparative studies of hearing in vertebrates. Springer, Berlin Heidelberg New York, pp 323-353

Sachs MB, Woolf NK, Sinnott JM (1980 b) Response properties of avian auditory nerve fibres and medullary neurones. Acta XVII Congr Int Ornithol 1978:710-713

Saito N (1980) Structure and function in the avian ear. In: Popper AN, Fay RR (eds) Comparative studies of hearing in vertebrates. Springer, Berlin Heidelberg New York, pp 241-260

Saunders JC, Denny RM, Bock GR (1978) Critical bands in the parakeet (Melopsittacus undulatus). J Comp Physiol 125:359-365

Scheich H, Langner G, Koch R (1977) Coding of narrow-band and wide-band vocalizations in the auditory midbrain nucleus (MLD) of the guinea fowl (Numida meleagris). I Comp Physiol 117:245-265

Scheich H, Bock W, Bonke D, Langner G, Maier V (1983) Acoustic communication in the guinea fowl (Numida meleagris). In: Ewert JP, Capranica RR, Ingle DJ (eds) Advances in vertebrate neuroethology. Plenum Publ, New York, pp 731-782

Schwarzkopff J, Bremond J (1963) Méthode de dérivation des potentials cochléailes chez l'oiseau. J Physiol (Paris) $55: 495-518$

Smith CA (1981) Recent advances in structural correlates of auditory receptors. Progr Sensory Physiol 2:135-187

Takasaka T, Smith CA (1971) The structure and innervation of the pigeon's basilar papilla. J Ultrastruct Res $35: 20-65$

Tanaka K, Smith CA (1978) Structure of the chicken's inner car: SEM and TEM study. Am J Anat 153:251-272

Walsh BT, Miller JB, Gacek RR, Kiang NYS (1972) Spontaneous activity in the eighth cranial nerve of the cat. Int $J$ Neurosci 3:221-236

Weiss TF (1966) A model of the peripheral auditory apparatus. Kybernetik 3:153-175 